\title{
Inhibiting NF-אB During Cytokine Storm in COVID-19: Potential Role of Natural Products as a Promising Therapeutic Approach
}

\section{Running title: Inhibiting NF-kB During Cytokine Storm in COVID-19}

Jalal Mardaneh ${ }^{1}$, Amirreza Nasirzadeh${ }^{1}$, Javad Bazeli ${ }^{2}$, Jafar Hajavi ${ }^{3}$, Mohammad Zahedi ${ }^{4}$, Mahdi Abounoori $^{5}$, Alireza Razavi ${ }^{5}$, Mohammad Moein Maddah 5 , Parham Mortazavi ${ }^{6}$, Mohammad Moradi ${ }^{7}$, Fatemeh Salehi ${ }^{8,9}$, Siamak Heidarzadeh ${ }^{10^{*}}$, Mohammad Hosein Jafarzadeh Maivan ${ }^{11^{* *}}$, Afshin Shoeibi ${ }^{12,13}$, Roohallah Alizadehsani ${ }^{14}$, Sheikh Mohammed Shariful Islam ${ }^{15,16,17}$

${ }^{1}$ Department of Microbiology, School of Medicine, Infectious Diseases Research Center, Gonabad University of Medical Sciences, Gonabad, Iran.

${ }^{2}$ Nursing Department, Nursing and Midwifery, Gonabad University of Medical Sciences, Gonabad, Iran.

${ }^{3}$ Department of Immunology, School of Medicine, Gonabad University of Medical Sciences, Gonabad, Iran.

${ }^{4}$ Department of Laboratory Sciences, School of Allied Medical Science, Student Research Committee, Mazandaran University of Medical Sciences, Sari, Iran.

${ }^{5}$ Medical Student, Student Research committee, Mazandaran University of Medical Sciences, Sari, Iran.

${ }^{6}$ Student Research Committee, School of Pharmacy, Mazandaran University of Medical Sciences, Sari, Iran.

${ }^{7}$ Resident of General Surgery, Iran University of Medical Sciences, Tehran, Iran.

${ }^{8}$ Department of Medical Laboratory Sciences, Zanjan University of Medical Sciences, Zanjan, Iran.

${ }^{9}$ Student Research Committee, Zanjan University of Medical Sciences, Zanjan, Iran

${ }^{10}$ Department of Microbiology and Virology, School of Medicine, Zanjan University of Medical Sciences, Zanjan, Iran.

${ }^{11}$ Student Research Committee, Gonabad University of Medical Sciences, Gonabad, Iran.

${ }^{12}$ Faculty of Electrical and Computer Engineering, Biomedical Data Acquisition Lab, K. N. Toosi University of Technology, Tehran, Iran

${ }^{13}$ Department of Computer Engineering, Ferdowsi University of Mashhad, Mashhad, Iran

${ }^{14}$ Institute for Intelligent Systems Research and Innovation (IISRI), Deakin University, Victoria, Australia

${ }^{15}$ Institute for Physical Activity and Nutrition, Deakin University, Melbourne, Australia

${ }^{16}$ Cardiovascular Division, The George Institute for Global Health, Australia

${ }^{17}$ Sydney Medical School, University of Sydney, Australia

\section{*Corresponding author}

Siamak Heidarzadeh

Assistant Professor of Department of Microbiology and Virology, School of Medicine, Zanjan University of Medical Sciences, Zanjan, Iran. E. mail: heidarzadehsiamak@gmail.com

\section{***Corresponding author}

Mohammad Hosein Jafarzadeh Maivan

Student Research Committee, Gonabad University of Medical Sciences, Gonabad, Iran.

\begin{abstract}
Many inflammatory mechanisms are involved in the pathophysiology of COVID-19 infection. COVID-19 inhibits IFN antiviral responses, so we should expect an out-of-control viral replication. "Cytokine storms" occur due to the over-production of pro-inflammatory cytokines after an influx of neutrophils and monocytes/macrophages and may be responsible for the immunopathology of the lung involvement. Several cascades have been reported in the activation process of NF- $\mathrm{KB}$. In this paper, to find new therapeutic options for COVID-19 infection, we reviewed some natural products that could potentially
\end{abstract}


inhibit the NF-kB pathway. We found that sevoflurane, quercetin, resveratrol, curcumin, KIOM-C, bergenin, garcinia kola, shenfu, piperlongumine, wogonin, oroxylin, plantamajoside, naringin, ginseng, kaempferol, allium sativum L, illicium henryi, isoliquiritigenin, lianhua qingwen, magnoflorine, and ma Huang Tang might be effective in inhibiting the NF-KB pathway. These natural products could be helpful in the control of COVID-19 infections. However, larger clinical trials are needed to ascertain the efficacy of these products fully.

Keywords: COVID-19, Pandemic, Natural Products, NF-KB.

\section{Introduction}

During a SARS-CoV infection, the viral antigen is recognized by the pathogen-associated molecular patterns (PAMPs) of the innate immune cells (1). Then PAMPs are identified by TLR-3, TLR-7, endosomal RNA receptors, and RIG-I/MDA5 (the cytosolic RNA sensor). When the viral antigens have been identified via PAMPs, downstream signaling pathways like NF- $\mathrm{BB}$ and IFR3 get triggered. Activation of these pathways contributes to the hyper-production of several pro-inflammatory cytokines. This situation is commonly known as a cytokine storm $(2,3)$. NF- $\mathrm{kB}$ is an upstream regulator of molecules such as IL-6, IL-8, TNF- $\alpha$, MMP, and ICAM-1 (4-6). Based on the recent reports about the SARS-CoV and MERS-CoV viruses, preventing the activation of these signaling pathways could significantly decrease the probability of cytokine storms. Moreover, frequent studies have emphasized the part of NF- $\mathrm{KB}$ in the pathogenesis of COVID-19 $(7,8)$. Chinese traditional medicine has a broad spectrum of therapeutic ranges. Recent studies have reported the anti-inflammatory role of some Chinese herbal medicines. Some of these natural products have the potency to reduce the inflammation caused by the NF- $\kappa$ B pathway. The inhibition of the NF- $\kappa$ B pathway by these herbs raises the possibility of them being effective as potential therapeutic options for COVID-19 infection.

\subsection{Virus Classification and Immune Response}

After the emergence of a new coronavirus in China in early 2020, a pandemic outbreak was announced by the World Health Organization (WHO) (9-13). Members of the Coronaviridae family, including SARSCoV-2, are enveloped by single-stranded RNA, positive-sense viruses $(1,14-17)$.

SARS-CoV-2 is composed of different structural and functional proteins. Structural proteins found on the SARS-CoV-2 membrane are E protein (envelope protein), M protein (membrane protein), and S protein (spike protein). The essential functional proteins in coronaviruses include helicase, RdRp protein, PLpro protein, and 3-CLpro protein. Both structural and functional proteins and some proteases are exclusively involved in the infection process, including intracellular virion transportation, proliferation, and assembling of the virions in host cells $(18,19)$. SARS-CoV-2 spikes allow it to stick firmly to ACE2. In addition, it is probably essential for inter-individual transmission (2).

The virus may diminish IFN antiviral responses causing an uncontrolled viral replication. Cytokine storms occur due to the over-production of pro-inflammatory cytokines after an influx of neutrophils and monocytes/macrophages and may be responsible for the immunopathology of the lung involvement. Th1/Th17 cell responses may also arise, leading to an aggravated inflammatory response in the patients. SARS-CoV-2 seems to share the entry receptor of ACE2, expressed by Type 2 alveolar cells and monocytes/macrophages in the lungs $(4,20-22)$.

Innate immune system cells identify the viruses invading the body by PAMPs. As mentioned earlier PAMPs are recognized by TLR-3, TLR-7, phagosomal RNA receptors, and RIG-I/MDA5 (the cytosolic 
RNA sensor). The identification of PAMPs by these receptors activates the downstream signaling pathways, such as NF-kB and IRF3, and their nuclear translocation. As the opening phase of defense in the case of COVID-19, the expression of Type-I IFNs and the other pro-inflammatory cytokines is elevated $(3,20)$. The JAK-STAT pathway, in turn, is activated by type I IFNs through IFNAR. So STAT1 and STAT2 are phosphorylated by the JAK-1 and TYK-2 kinases. The phosphorylated STAT1 and STAT2 are embedded in a complex with IRF9. This complex enters the nucleus of the cell to induce the transcription of ISGs within the limits of promoters of the ISRE. An acceptable ascent of the Type-I IFN response could probably inhibit the viral replication and its progression in the body at the start point (20, $23,24)$.

\subsection{Virus complications}

Several complications have been reported due to SARS-CoV-2 infection, including fever, cough, and sore throat. Cases such as diarrhea, chest pain, and nausea also were observed in some patients (25). Moreover, some organ damages like acute kidney injury, cardiac injury, and lung injury were reported (26).

\subsection{ALI and ARDS}

During ALI, lung capillaries become permeable leading to inflammation. This condition occurs due to endotoxemia (27). A severe ALI condition also is called ARDS, takes place despite an endotoxin shock (28). In both of these conditions, the pro-inflammatory cytokines increase because the immune system is over-activated. Thus therapies in which the immune system is being suppressed are particularly essential (6).

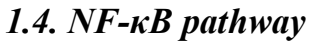

$\mathrm{NF}-\mathrm{\kappa B}$ is a nuclear transcriptional factor. It possesses many structural proteins which form both homoand heterodimers. The Rel/NFkB dimer is composed of p50-RelA (p65) and is the most typical dimer in mammals (5). NF- $\mathrm{BB}$ potentially cooperates to regulate lots of effector genes that encode the cytokines and adhesion molecules like TNF- $\alpha$, IL-6, IL-8, MMP-9, and ICAM-1 (29, 30). Figure 1 illustrates the $\mathrm{NF}-\kappa \mathrm{B}$ signaling pathway precisely. 


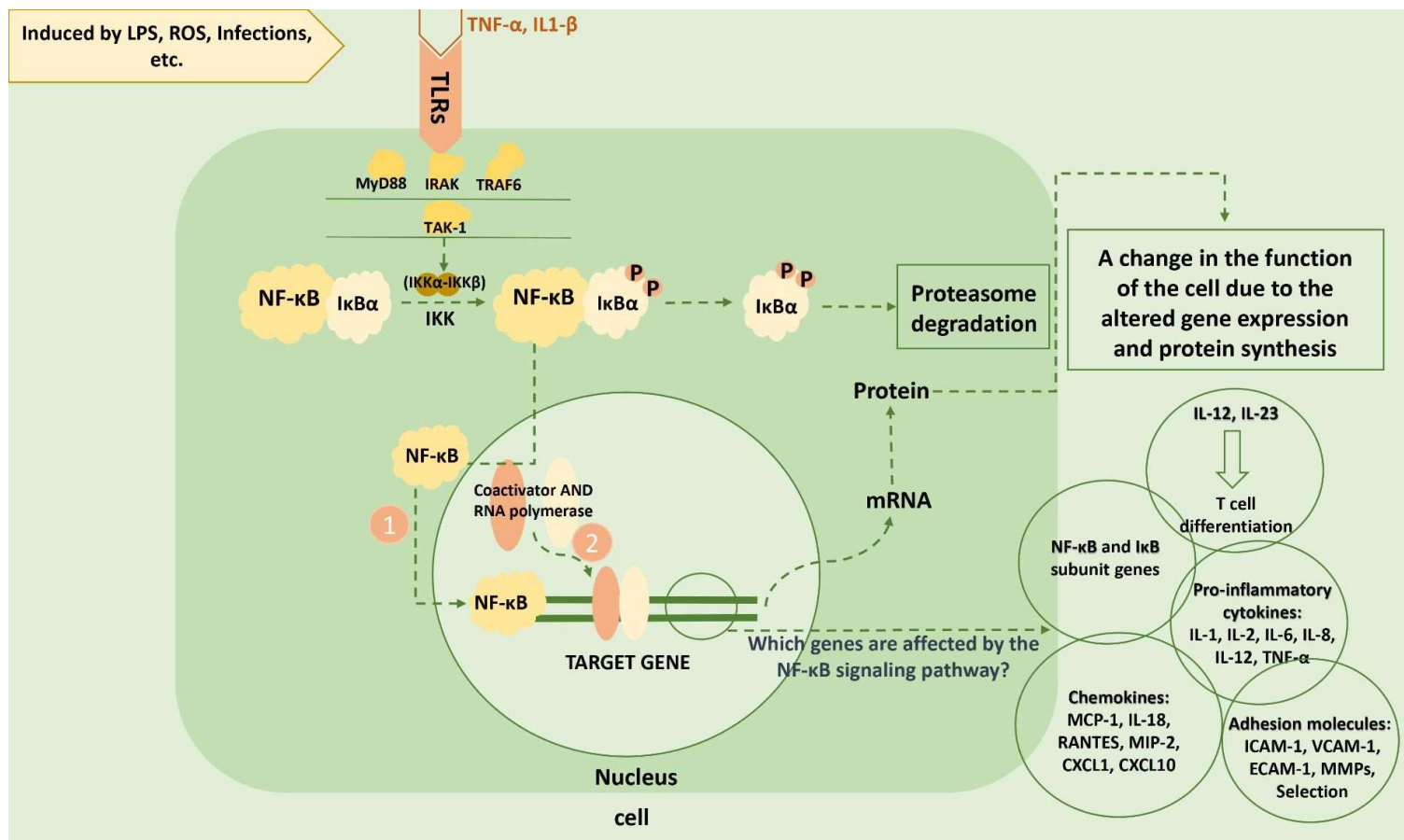

Fig 1. NF- $\kappa B$ signaling pathway. TNF- $\alpha$, IL1- $\beta$, which are over-secreted induced by COVID-19 infection, are recognized by TLRs. Then IKK gets activated by the mediation of MyD88, IRAK, TRAF6 and TAK-1. IKK phosphorylates IкB $\alpha$

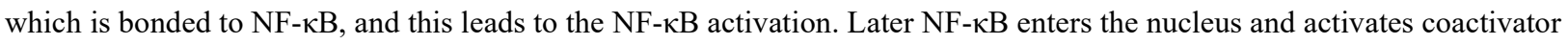
and RNA polymerase to express specific genes, as shown in the figure.

Several cascades have been reported that get triggered by the activation of NF- $\kappa \mathrm{B}$. One of these cascades starts with the binding of TNF- $\alpha$ to its receptors (TNFR1 /TNFR2) $(31,32)$ which requires TRAF2, RIP, and NIK, all of them trimerized (33). NIK then both phosphorylates and starts-up IkB kinase (IKK) (34), which subsequently targets IkBa to attach it to ubiquitin and move it towards the proteasome in order to get it degraded. Another cascade occurs through the activation of PI3K by TNFR1 and its downstream target, Akt kinase (protein kinase B), which mediates the activation of NF- $\mathrm{kB}$ by promoting TNF- $\alpha$ (35).

HMGB1 protein is notorious for causing inflammation and cell damage. This protein is secreted to the extracellular matrix by stimulating inflammatory factors like LPS (36). It could take part as a DAMP (37), a perpetual part of many clinical conditions, such as ALI/ARDS, sepsis, asthma, and cancers (38, 39).

HMGB1 protein activates the inflammation-related signaling pathways through binding to a receptor for AGE's and the TLR-2/4. NF- $\mathrm{KB}$ and MAPK are two of these pathways that are flourished by overproduction of the downstream pro-inflammatory mediators, TNF- $\alpha$, IL-1 $\beta$, and IL-8 (40). There is some evidence that better therapy results could be achieved in LPS-induced ALI/ARDS by prohibiting the HMGB1-mediated TLR4/NF-kB signaling pathway $(7,8)$.

Some studies have introduced NF- $\mathrm{kB}$ as a significant factor in the pathogenesis of coronaviruses. A study by Dediego et al., also demonstrated the crucial role of NF- $\mathrm{kB}$ in the pathogenesis of SARS-CoV-2 due to different cytokines expression and inflammation. This study suggested that the inhibition of this pathway might be a viable solution to reduce inflammation caused by SARS-CoV-2 and the other coronaviruses (41). 
Gupegui et al., also showed the role of this pathway in MRES-CoV pathogenicity (42). Sallenave et al., introduced NF- $\mathrm{KB}$ as a crucial factor in new coronavirus pathogenesis and suggested that inhibition of this pathway might be helpful in the treatment of COVID-19 (43). A recent research revealed the efficiency of some natural products to inhibit the NF- $\mathrm{KB}$ pathway (44).

APCs can activate the NF- $\mathrm{kB}$ signaling pathway in different ways. Presentation of the SARS-CoV-2 antigens to CD4 plus T-helper cells through MHC class I molecules and recognition by APCs, is one way to activate the NF- $\mathrm{KB}$ signaling pathway. Viral antigens also can cause the release of IL-12 and subsequently motivate the activation of Th1 cells. As stated before, the activation of NF- $\kappa B$ induces the hyper-production of some pro-inflammatory cytokines. Among them, elevated levels of IL-17 have been observed the most in SARS-CoV-2 infection. These cytokines can mostly absorb neutrophils and monocyte to the site of infection; and activate some other chemokines and pro-inflammatory cytokines, namely IL-1, IL-6, IL-8 IL-21, TNF- $\beta$, and MCP-1 (45-48).

Moreover, APCs can distinguish the protein spike of SARS-CoV-2 by TLR-4. This differentiation leads to stimulation of the NF- $\kappa \mathrm{B}$ and MAPKs pathways through Myd88`s mediation which can cause the production of inflammatory proteins. On the other hand, diagnosis of ssRNA or dsRNA genome of the coronavirus through the activation of TLR7/8 and TLR3 can recruit TRIF adaptor proteins which in turn activate IRF3 and NF- $\mathrm{KB}$ transcription factors and stimulates the production of pro-inflammatory cytokines such as TNF- $\beta$ and IFN- $\alpha(20,45,46,49)$. Overexpression of different cytokines can lead to a cytokine storm, which may gradually turn to ARDS. This information can be observed at a glance in figure 2. Given this background and prior research, we aimed to investigate potentially beneficial Chinese herbs that play a promising role in inhibiting the NF- $\mathrm{KB}$ pathway. If proven to behave as predicted, they could be a possible candidate for the management of ALI (50-52).

\subsection{Summary of herbs}

\subsubsection{Sevoflurane:}

Sevoflurane is an inhaled, sweet-smelling, methyl isopropyl widely used in general anesthesia. Inhalation of sevoflurane has anti-inflammatory and protective effects in some inflammatory processes such as sepsis or ischemia/reperfusion of blood flow in the heart, brain, kidneys, and liver $(53,54)$. It could also prevent ALI and liver ischemia/reperfusion (IR) $(55,56)$. The inhibitory effect of sevoflurane on LPS has been shown both in vivo and in vitro studies $(55,57,58)$.

Sevoflurane improves resistance cytokine storms by lowering serum levels of IL-1 and -6 , IFN- $\gamma$, and TNF- $\beta$. Moreover, sevoflurane has been shown to reduce NF- $\kappa B$ expression by increasing miR-9-5p expression and decreasing p56 factor expression; therefore, it helps protect the liver from IR damage (56). 


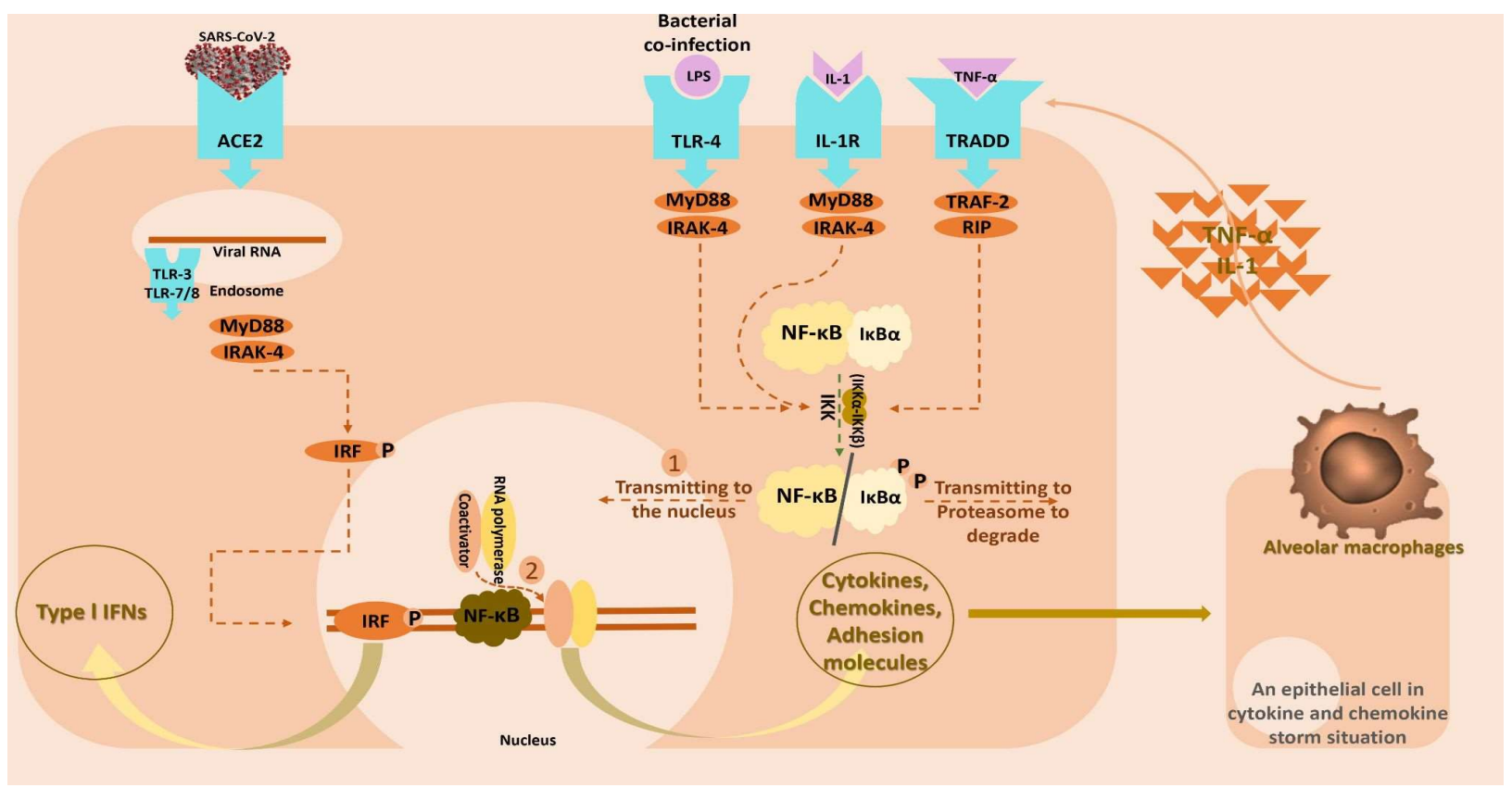

Fig 2. The correlation between cytokine storms induced by COVID-19 infection and NF- $\kappa$ B signaling pathway. SARS-

CoV-2 can bind to ACE2 receptors as an entry point to the cell. Viral RNA in the endosome through TLR-3/7/8 and by the mediation of MyD-88 and IRAK-4 phosphorylates IRF. Then phosphorylated IRF in the nucleus induces the type I IFNs gene expression. The over-secretion of TNF- $\alpha$ and IL1- $\beta$ by cells such as alveolar macrophages NF- $\kappa$ B pathway gets activated.

Recent research based on the western-blot technique shows that sevoflurane could improve the damages caused by inflammatory responses via blocking miR-27a, TLR4, MyD88, and NF-אB signaling pathway in airway smooth muscle cells (59). As a result, the lungs are protected from ALI $(55,60)$. It also increases the synthesis of PGE2 by COX-2 in peritoneal macrophages, which attenuates the severity of ALI $(3,54)$. So, it could be effective in COVID-19 infection.

\subsection{Quercetin:}

Quercetin is a plant flavonol from the flavonoid group of polyphenols. Both in vivo and in vitro studies demonstrated anti-inflammatory, antiviral, anti-microbial, antitumor, and antioxidant effects of quercetin. It also reduces the risk of cardiovascular disease $(23,24)$. Previous studies have shown that quercetin downregulates NF- $\mathrm{B}$ s signaling pathways, leading to some anti-inflammatory impacts (61-64). Quercetin notably blocks LPS-induced production of NO, IL-1, iNOS, COX-2 (65) and inhibits the release of IL-6, CXCL10, MCP-1, RANTES, TNF- $\alpha$, G-CSF, GM-CSF, LIX, VEGF, and LIF as well as calcium release in dsRNA induced with polyinosinic-polycytidylic acid (66).

Quercetin restricts LPS-induced inflammation through the blockage of Src- and Syk-mediated PI3K-(p85) tyrosine phosphorylation and also blockage of ensuing complex formation of TLR4, MyD88 AND PI3K. The complex downscales the activation of downstream signaling pathways. It also promotes the function of HO-1 in a dose and time-dependent manner. The phosphorylation of IKB, translocation of NF- $\mathrm{kB}$, binding of NF- $\mathrm{KB}$ to AP-1, and transcriptional reporters are also suppressed by quercetin (65). It has been demonstrated that quercetin could reduce ICAM-1, both mRNA and protein levels, and also MCP-1 dosedependently. Reduction of ICAM and MCP-1 is achieved by inhibiting the inflammatory signaling pathways, phosphorylation of MAPKs, an inhibitor of (IKK) $\alpha / \beta$, and activating ATF2, which eventually 
leads to blockage of the NF-kB p65 transmission to the core (62). Due to Quercetin's inhibitory and suppressor effects on the inflammation and cytokine storms $(67,68)$, it can be a potential therapeutic option for the COVID-19 infection.

\subsection{Resveratrol:}

Resveratrol is a stilbenoid, and a phytoalexin generated in several plants when they get hurt or some pathogens such as bacteria or fungi attack them. It has been found the most in the red grapes (69). Resveratrol has antioxidant (70), antitumor (71) and anti-inflammation (72) properties. Resveratrol therapy significantly diminishes the permeability of the pulmonary arteries. It also lowers the probability of cytokine storms caused by staphylococcal enterotoxin B and the resulting inflammation. This cytokine storm usually occurs after an increase in the caspase-8-dependent apoptosis in the SEB activated T cells. Resveratrol therapy significantly regulates myeloid Cd11b and Gr1 suppressor cells, thereby inhibiting the activation of SEB-mediated $\mathrm{T}$ cells under laboratory conditions. In addition, resveratrol therapy is associated with SIRT1 regulation and NF- $\kappa$ B down-regulation in the inflamed lung cells $(73,74)$. In another study, the administration of resveratrol significantly reduced spinal cord injury and also induced pulmonary edema (39).

Also, Resveratrol significantly reduces the neutrophils penetration and the inflammatory mediator's production. Resveratrol treatment was associated with careful regulation of SIRT1 expression and suppressing NF- $\mathrm{kB}$ activity in the lung tissue. Based on this evidence, resveratrol might be useful in treating COVID-19 infection $(75,76)$.

\subsection{Curcumin:}

Curcumin is a lemon-yellow chemical is synthesized by Curcuma longa plants. It is the main curcuminoid of turmeric, a member of the ginger family, Zingiberaceae. This substance has anti-inflammatory, antimicrobial, antiviral, and antioxidant properties (77-79) partly because it influences the activity of COX-2, lipoxygenase, and iNOS enzymes. It cooperates to inhibit the production of inflammatory cytokines such as TNF- $\alpha$, MCP-1, IL-1, IL-2, IL-6, IL-8, and IL-12 (80).

Administration of curcumin to minimize the lung involvement induced by intestinal ischemia-reperfusion injury (IIR) attenuated the inflammatory indicators such as MPO activity, IL-6, and ICAM-1 level. Attenuating these levels subsequently leads to the inhibition of the NF- $\mathrm{KB}$ pathway, in parallel reducing the SOD activity. Thus it has been shown that the NF- $\mathrm{kB}$ pathway gets inhibited through the antiinflammatory and antioxidant effects of Curcumin (81).

Another study showed that curcumin could affect the immune system by changing the IL-1 $\beta$, IL-4, and VEGF in the blood (82). In one study, curcumin was used to control liver toxicity caused by the oral administration of CCl4. Using $\mathrm{CCl} 4$ increases the levels of inflammatory mediators involved in liver damage such as TNF- $\alpha$, IL-1 $\beta$, and IL-6, which were dramatically suppressed by curcumin. CCl4 transmits NF- $\kappa B$ to the nucleus and the NF- $\kappa B$ DNA is prevented from binding to $\mathrm{CCl} 4$ by using curcumin (83). In a study on the effects of curcumin on Cardiac Ischemia/Reperfusion during cardiopulmonary bypass (CPB), levels of IL $-8, \mathrm{IL}-10$, TNF- $\alpha$, and cardiac troponin I, which increases due to heart damage, were significantly lower in the group receiving curcumin. In addition, apoptotic cardiomyocytes have been shown to decrease in those patients. Myocardial neutrophil activation, which is measured using myocardial MPO activity, was significantly reduced as well. In comparison, the group that did not receive curcumin saw a significant increase in the fracture fragments associated with apoptosis from Caspase 3 and poly-ADP-ADP-ribose polymerase. As a result, curcumin prevents NF- $\mathrm{B}$ 
inhibition, increases inflammatory cytokines during $\mathrm{CPB}$, and reduces the incidence of cardiomyocyte apoptosis after cardiac ischemia/reperfusion injury (84).

Another study found that curcumin inhibits NF- $\mathrm{B}$ transport to the nucleus by inhibiting IKK $\beta$, contributing to the stabilization of NF- $\mathrm{KB}$ inhibitor, IkBa, in the prostate cancer cells, PC-3. Controlling $\mathrm{NF}-\kappa \mathrm{B}$ activity reduces CXCL1 and -2 expression and eliminates the autocrine/paracrine ring that binds two chemotherapeutic compounds to NF- $\mathrm{kB}$. Finally, curcumin reduces the formation of metastases in vivo by inhibiting NF- $\kappa$ B signaling and disrupting this feedback loop (85). Due to the anti-inflammatory and antioxidant activities of curcumin in the heart (86), lungs (87), liver (88), and kidneys (89), it might help the treatment of COVID-19 disease quite well.

\subsection{KIOM-C:}

KIOM-C is a combination of several herbal medicines, including Platycodon grandiflorum, Angelicae Gigantis, Radix Glycyrrhizae, Radix, Zingiber officinale, Radix Paeoniae Alba, Radix Scutellariae, and Lonicera japonica Thunb. It possesses anti-H1N1 influenza effects (90-92).

An array of studies have shown that pigs grow better by consuming KIOM-C. It also protects their bodies against PCVAD (93).

In an in vitro study on mice by Talactac et al., antiviral activities of KIOM-C against H1N1 influenza (PR8), vesicular stomatitis virus, and Newcastle disease virus (94) were demonstrated. These effects are through the induction of protein phosphorylation (IRF3, p65, STAT1, TBK1, p38, and ERK), IFN type I and ISGs, and also the regulation of inflammatory cytokines (TNF- $\alpha$, IL-6, IL-12) (RAW264.7). In an in vivo study, a BALB/c mouse treated with KIOM-C could survive longer and had lower viral titers against $\mathrm{H} 5 \mathrm{~N} 2, \mathrm{H} 1 \mathrm{~N} 1, \mathrm{H} 7 \mathrm{~N} 3$, or H9N2 in comparison to the untreated group (95).

Another study examined how KIOM-C influences the metastatic potential of HT1080 and B16F10 cells and whether it decreases the pace of tumors getting metastatic. Using KIOM-C to inactivate NF- $\mathrm{KB}$ reduces the activity of MMP-9 in the resting and stimulating state of PMA dose-dependently in HT1080 cells. Frequent oral administration of KIOM-C efficiently reduced lung metastasis to B16F10 cells (96). In the EH Kim study, oral administration of KIOM-C has been shown to boost the production of antiviral cytokines, such as IFN- $\gamma$ and TNF- $\alpha$, reduce the levels of inflammatory cytokines like IL-6, and also chemokines like MCP-1 in mice infected with H1N1 flu BAL (90). Therefore, this drug might be helpful in the treatment of COVID-19 infection.

\subsection{Bergenin:}

Bergenin, which is also called Cuscutin, is a trihydroxy benzoic acid glycoside. It is the C-glycoside of 4O-methyl gallic acid. It has an O-demethylated derivative known asnorbergenin and shows a potent immunomodulatory effect (97-99). In the Yang study, Bergenin reduced inflammatory cells and produced IL-1 $\beta$ and IL-6 in BALF through the expression of MyD88 protein and the inhibition of NF- $\mathrm{BB}$ P65 phosphorylation and nuclear translocation in Raw264.7 cell lung tissue. It also produced TNF- $\alpha$, IL-1 $\beta$, and IL-6 in the serum of mice dealing with ALI caused by LPS (100).

As a PPAR- $\gamma$ agonist, Bergenin reduces TNF- $\alpha$ and IL- 6 expression by improving the presentation of SIRT1 and inhibiting NF- $\kappa B$-mediated macrophage activation (101). In a study by X Gao et al., Bergenin suppressed the expression of NO, IL- $1 \beta$, TNF- $\alpha$ and IL- 6 by getting NF- $\kappa B$ and MAPKs signaling pathways inactivated. This may introduce a new therapeutic option for reducing inflammation of the lung tissue caused by LPS (102). Thus, Bergenin might be helpful to the treatment of COVID-19. 


\subsection{Kolaviron}

Kolaviron is mainly obtained from Garcinia kola extract (103), a species of Angiosperms in the Clusiaceae family $(104,105)$. It possesses antihepatotoxic (106), antioxidant, and antiseptic properties (107). In Abarikwu et al. (2014), when pre-treated macrophages with Kolaviron (Kol-V) were stimulated

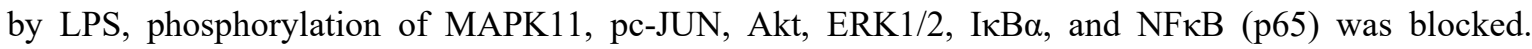
However, Kol-V failed to block the phosphorylation of CREB. In addition, Kol-V inhibited the expression of CXCL10 mRNA but did not affect LPS-induced reduction in cytokines expressions such as IL-1 $\alpha$, IL-1 $\beta$, IL-33 and IFN $\beta 1-1$. Kol-v also showed some protective effects on phosphorylation of LPS kinase protein activated by MAPK, a member of the JNK family. In all Kol-V concentrations, there were no effects induced by Kol-v on LPS-induced TNF- $\alpha$ inflammatory cytokine secretion. Still, inhibition of Kol-v concentration was observed in IL-6 secretion. Kolaviron reduced pulmonary expression of IL-1b, RANTES, IL-10, MCP-1, NF- $\mathrm{B}$, iNOS, and COX-2 (108). Therefore, it might have a potential role in treating COVID-19 due to its antioxidant properties and the potential to suppress cytokine storms.

\subsection{Shenfu:}

Shenfu is a traditional Chinese natural product. It has been approved by the Chinese State Food and Drug Administration. It originates from Ginseng Radix et Rhizoma Rubra and Aconiti Lateralis Radix Praeparata. The anti-inflammatory effects of Shenfu are well-known in China. Shenfu injection is approved in treating septic shock (109). Shenfu can raise superoxide dismutase activity and has some antioxidant effects by removing oxygen free radicals and inactivating xanthine oxidase (110). Shenfu also has a $\mathrm{Ca} 2+$ regulating effect which is achieved through blocking the intracellular $\mathrm{Ca} 2+$ channel and preventing intracellular Ca2+ overload (111).

In vivo studies convey that Shenfu might inhibit the generation of pro-inflammatory cytokines such as TNF- $\alpha$ and IL- 6 beyond the dose and also prevent their production in the lungs. Besides, Shenfu can suppress their gene regulator, NF- $\mathrm{kB}$ (112). A Shenfu injection could significantly reduce complement components like $\mathrm{C} 3, \mathrm{C} 4$, and $\mathrm{C} 5 \mathrm{~b}-9$ as well (113).

Shenfu reduces neutrophil accumulation into the lung tissue through its apparent suppression of NF- $\mathrm{BB}$ and other pro-inflammatory cytokines. Thus, it has a protective effect against pulmonary edema (112). In addition, Shenfu could prevent translocation of NF- $\mathrm{BB}$, but it's unable to prevent the production of TNF- $\alpha$ in the lungs. This is because though NF- $\mathrm{KB}$ is the key upstream regulator of TNF- $\alpha$, it is not the only one. Secondly, it is partially inhibited by the anti-NF- $\kappa B$ pathway (114).

\subsubsection{Piperlongumine:}

Piperlongumine (PL) is an active dihydropyridine alkaloid (115). It is extracted from Piper Longum and long pepper plants (116). It has insecticidal, antibacterial, anticarcinogenic, antidiabetic, anti-platelet aggregation, and anti-fungal properties $(115,117-121)$.

PL acts via ROS-dependent apoptotic pathways mediated by $\mathrm{H} 2 \mathrm{O} 2$ and $\mathrm{NO}$ (122). In vitro studies showed that administration of PL could attenuate TNF- $\alpha$ levels. In addition, it significantly blocked the nuclear translocation of p50 and p65 (122). PL not only attenuated NF- $\mathrm{kB}$ translocation but also attenuated ph-Akt and its downstream targets (123). IL-6, IL-8, ICAM-1, and MMP-9 also decreased significantly by using PL due to attenuated activation of NF- $\mathrm{KB}$ (124). Several in-vitro studies have shown the anti-inflammatory impacts of PL, which acts through inhibition of LPS-induced inflammation, collagen-induced arthritis, and neuroinflammation (125-127). Robust evidence indicates that PL exerts its anti-inflammatory effects through the down-regulation of NF-kB $(128,129)$. 


\subsubsection{Wogonin:}

Wogonin is a component obtained from nature belonging to the bioflavonoids and extracted from the roots of Scutellaria baicalensis Georgi (130-132). Wogonin inactivates the NF- $\kappa B$ pathway, which leads to suppression of LPS-induced expression of iNOS, NO, TNF- $\alpha$, and IL-1 $\beta(133,134)$.

In vivo studies demonstrated that Wogonin turns off IL-6 and IL-8 gene expression; it also stops NF-kB binding to the DNA, contributing to down-regulation of inflammation-associated protein COX-2 production and preventing the inflammation. Available data show that Wogonin could be beneficial to treat inflammatory diseases, including COVID-19 infection (135).

Furthermore, Wogonin can inactivate TLR4 adaptors (MyD88 and TAK1) in LPS-induced inflamed cells (136). Also, in vitro studies showed promising evidence that Wogonin can inhibit LPS-induced inflammation via inhibition of the TLR4/ NF- $\kappa$ B pathway and reduce IL-6, IL-8, IL-1 $\beta$, TNF- $\alpha$, COX-2, and iNOS gene expression (137). Other studies also revealed that Wogonin could reduce proinflammatory mediators in LPS-induced inflammations, including COX-2, iNOS, IL-1B, IL-6, and TNF- $\alpha$ through the inhibition of NF- $\kappa B$ and MAPKs signaling pathways (138).

\subsubsection{Oroxylin A:}

Oroxylin A (OroA) is an active Polyphenol compound extracted from Scutellariae radix. This compound has anti-inflammatory, antipyretic, analgesic, and antitumor properties $(139,140)$.

In vivo studies on rodents demonstrated that OroA significantly lowers the lung inflammation severity and the mortality rate of LPS-induced ALI. OroA profitably suppresses the NF- $\kappa B$ signaling pathway, which contributes to lessening the inflammation severity and probability. It significantly obstructs the elevated circulating TNF- $\alpha$ levels and NO release of the nuclear HMGB1 into the cytoplasm. OroA also prevents the accretion of macrophages and neutrophils in the tissue space. Furthermore, OroA restrains the intra-alveolar septa of the lungs from thickening (141).

Evidence shows that OroA could attenuate the formation of pulmonary edema by protecting endothelial function to alleviate neutrophil sequestration. Although the overproduction of NO and TNF- $\alpha$ causes injury to vascular endothelial cells and an increase in permeability of lung vessels, OroA could alleviate vascular damage by reducing these mediators (142).

iNOS and two other enzymes generate NO, a potent lung vasodilator, from L-arginine in the alveolar macrophages. OroA restrains iNOS gene expression, so it stops the alveolar macrophages producing NO and reduces inflammation in the lungs (143).

OroA reduces the cytokine release during and following the inflammation and prevents the irremediable damages caused by the release of HMGB1. Also, since OroA has anti-NF- $\kappa \mathrm{B}$ properties, it blocks the release of LPS-induced NO (143). In vivo studies reported that OroA has a dramatic potency to ameliorate asthma by inhibiting ovalbumin (OVA)-induced lung histopathologic changes mediated by NF- $\kappa B$ activation, AHR, the levels of OVA-specific IgE in serum, and Th2 cytokines in BALF (144). OroA also could act against human tumor cells through inducing apoptosis and cell cycle arrest and through the anti-invasion function (145).

\subsubsection{Plantamajoside:}

Plantamajoside (PMS) is a unique compound identified as a phenylpropanoid glycoside (146). It is a principal constituent extracted from Plantago asiatica L. (Plantaginaceae) and has been recognized for its broad bioactivities such as antioxidant, anti-proliferative, antitumor, antiviral, diuretic, and anti- 
inflammatory properties (146-150). PMS could exert anti-inflammatory influences (150), and no adverse effects were reported induced by the oral administration until 90 days (151).

The distinct character of LPS-induced lung inflammation is pulmonary edema (152). The infiltration of the activated neutrophils into the lungs and the production of the MPO $(153,154)$, which is the main ingredient of neutrophils cytoplasmic granules, is always observed in the ALI inflammatory response (155). IL-6, IL-1 $\beta$, and TNF- $\alpha$ are some predictive markers in ALI, and let us know if the ALI will respond to the treatment by PMS or not (75).

PMS showed an anti-inflammatory potency in vivo by reducing IL-6, IL-1 $\beta$, TNF- $\alpha$ and also increasing IL-10 dose-dependently (156). This dramatic effect is achieved by inhibiting NF- $\mathrm{kB}$ and MAPKs phosphorylation in LPS-induced ALI (157). PMS could efficiently protect advanced glycation endproduct-induced endothelial cells (AGEs) against inflammatory cellular dysfunction (158). Thus, PMS can protect the body against many respiratory inflammatory diseases, namely asthma and chronic obstructive pulmonary disease (COPD) (159).

\subsubsection{Naringin:}

Naringin is a flavanone glycoside mostly found in grapes and citrus fruits. It has antioxidant, antibacterial, anti-atherosclerosis, anti-inflammatory, and anti-hyperlipidemic properties and could efficiently lower blood glucose levels (160-166).

In vitro and in vivo studies have asserted that Naringin attenuates the effects of ALI through alleviating pathological lung changes and facilitating the LPS-induced sepsis model via inhibition of the NF- $\mathrm{KB}$ signaling pathway $(167,168)$. Naringin could reduce the release of TNF- $\alpha$ and HMGB1 from the macrophages stimulated by LPS (169). Moreover, it elevates the anti-inflammatory IL-10 and decreases the release of pro-inflammatory cytokines such as IL-6 and neutrophils MPO $(163,170)$.

Flavonoids, a class of polyphenolic secondary metabolites in plants, possess antiviral properties (171). In a vast majority of COVID-19 patients who show increased levels of TNF- $\alpha$, IL- $1 \beta$, and IFN- $\gamma$, cytokine storms have been observed. LPS is the main constituent of the outer membrane of all Gram-negative bacteria. It induces an increase in cytokines such as TNF- $\alpha$, IL- $1 \beta$, IL-6, IFN- $\gamma$, and MCP-, 1, leading to a cytokine storm (172). It is concluded that Naringin (at concentrations of $10,20,40 \mu \mathrm{g} / \mathrm{mL}$ ) has the potency to reduce inflammatory cytokines such as IL-1 $\beta$, and IL-6, and subsequently COX-2, iNOS via the inhibition of p38 MAPK and HMGB-1 signaling pathways (173). Several studies on 2019-nCoV binding sites showed that this virus has a high affinity to the human ACE2, which is widely expressed in the kidneys, lung, brain, and digestive tract (174).

Results demonstrated that Naringin might have the highest binding activity to the ACE2 among citruses, close to chloroquine docking energy. This restrains the virus from attaching to the ACE2 and blocking it $(173,175)$. Several studies have demonstrated that increased levels of TNF- $\alpha$ could lower the survival of osteoblast cells and differentiation from its precursors, even though it is reported that Naringin at a high dose can alleviate the TNF- $\alpha$-associated osteoporosis via inhibition of the NF- $\kappa B$ signaling pathway (176, 177). Sometimes, the activation of the NF- $\mathrm{KB}$ signaling pathway could be due to free radicals, which would subsequently cause inflammation. At a dosage of $100 \mathrm{mg} / \mathrm{kg}$, Naringin could significantly reduce oxidative stress and decrease the levels of oxidative enzymes. Also, it could decrease the MPO levels, NF- $\mathrm{kB}-\mathrm{DNA}$-binding activities, and pro-inflammatory cytokines, such as IL- 6 and TNF- $\alpha$, which lead to inflammation suppression (178). 


\subsubsection{Ginsenoside:}

Ginseng is the root of the Panax ginseng C.A. Meyer plant. Studies have shown that the Re and $\operatorname{Rg} 6$ types are effective in the immune system as an anti-inflammatory drug $(179,180)$.

Ginsenoside can inhibit IKK- $\beta$ phosphorylation, NF- $\kappa$ B activation, and the expression of inflammatory cytokines like TNF- $\alpha$ and IL-1 $\beta$, LPS induced IRAK-1 phosphorylation and degradation of IRAK-1 and IRAK-4 in the LPS-stimulated peritoneal macrophages. However, it still does not act on TNF- $\alpha$ or PGstimulated peritoneal macrophages $(179,181-183)$. In addition, Ginsenoside blocks the binding of LPS to TLR4 on peritoneal macrophages in the inflammatory processes.

Studies have shown that oral administration of Ginsenoside significantly inhibits the expression of IL-1 $\beta$ and TNF- $\alpha$ in LPS-induced systemic inflammation and TNBS-induced colitis $(179,184-186)$. An in vivo study demonstrated that Ginsenoside down-regulates the NF-אB pathway in TNBS-treated mice (179).

Ginsenoside $\operatorname{Rg} 6$ is a rare type of Ginsenoside that can regulate inflammation reactions, reduce neutrophil infiltration, expression of TNF- $\alpha$ and increase serum levels of IL-10. Rg6 inhibits inflammatory signals like NF- $\kappa$ B activator and MAPKs $(180,182,185,187,188)$. Additionally, Rg6 induces an operator of miRNA called miR-146a as an anti-inflammation substance (180). Ginsenoside can have some magnificent anti-inflammatory effects that might be helpful in the COVID-19 therapy.

\subsubsection{Kaempferol:}

Kaempferol contains flavonoid compounds that can effectively prevent lung inflammatory diseases like influenza and ALI. Based on recent studies, this substance has reduced the production of ROS and MDA. Also, this natural drug decreases the production of inflammatory cytokines, such as TNF- $\alpha$, IL- 6 , and IL$1 \beta$, helping to the down-regulation of the lung tissue inflammation (189-193). In the inflammatory pathways, Kaempferol upregulates TLR4, MyD88, and NF- $\mathrm{kB}$ p65 DNA binding activity (194). Also, it can suppress the MAPKs level (195).

A recent study regarding Kaempferol on H9N2 influenza virus demonstrated that Kaempferol produces an effect that protects the body from the virus invasion and the subsequent inflammation through TLR4/MyD88 suppression and also the NF- $\mathrm{KB}$ and MAPKs pathways (195).

Another investigation assessed the effects of Kaempferol on LPS induced ALI in vivo (196). It showed that Kaempferol suppresses the MAPKs and NF- $\mathrm{KB}$ signaling pathways, which probably are responsible for tissue oxidative injury and inflammation reactions of the lungs $(196,197)$. Therefore, Kaempferol might help inhibit pulmonary inflammation, one of the most critical obstacles in treating the COVID-19 infection.

\subsubsection{Allium sativum $L$. :}

Allium sativum L. is the scientific name of garlic. Garlic possesses anti-carcinogenic and anti-infection properties and is protective against cardiovascular disease (198-202). The chemical substance extracted from garlic is called methyl 3-formyl-4methykpentanoate (SMFM), potentially inhibiting lung inflammation. It also inhibits NO, PGE, TNF- $\alpha$, IL-6, and IL-1 $\beta$ as inflammatory factors in LPS-induced infections $(24,203-206)$.

In a study on Cecal ligation and puncture (CLP), an experimental polymicrobial sepsis model in mice, SMFM decreased bacterial peritoneal fluid infections and inhibited the production of pro-inflammatory cytokines. Moreover, lymphocyte apoptosis decreased in the spleen (24). In another in vitro study, macrophages survived using SMFM substance in LPS-induced inflammation. The findings included the 
inhibition of NO, PGE, TNF- $\alpha$, IL- $1 \beta$, COX-2, and NF- $\kappa$ B protein expression and transcription (206). As previously noted, inhibition of NF- $\mathrm{KB}$ signaling can help to treat COVID-19 infection.

\subsubsection{Illicium henryi:}

Illicium henryi is a medical plant used in traditional medicine, especially in eastern Asia and China (207). Studies report that this plant possesses antioxidative and antiviral properties, especially against HBV and HIV (208). This root contains flavonoids like quercetin, neolignans, sesquiterpene, ligans, and glycosides, which are the origins of the antioxidant and anti-inflammatory properties (209-211).

Two recent in vivo studies confirmed the effects of the Ethanol extract (EEIH) of Illicium henryi (EEIH) on LPS-induced acute liver and kidney injury and acute kidney injury in mice $(185,186,212)$. The first study, which has focused on LPS-induced AKI in mice, showed that EEIH significantly decreased serum creatinine and blood urea nitrogen rates in mice. EEIH restrained the expression of TNF- $\alpha$, IL-1 $\beta$, and IL6 and the production of COX-2 by downregulating TLR4 and NF- $\kappa \mathrm{B}$ phosphorylation dose-proportional manner during inflammation (213).

The other observed effects were reducing NO, MDA, and glutathione and decreased SOD levels (185, 214, 215). The second study evaluated EEIH effects on LPS-induced ALI. They showed that EEIH reduced the expression of pro-inflammatory factors, including TNF- $\alpha$, IL-1 $\beta$, IL- 6 , and COX-2, based on the exact mechanism employed by the other investigation. Like the former study, NO, MDA levels decreased, and a reduction in SOD levels was observed. Upregulation of Nrf2 was observed as well (185, 216). According to these studies showing the suppression effects of this drug on the TLR4/NF- $\mathrm{KB}$ pathway, it can treat inflammation, and therefore might be useful in treating COVID-19 infections.

\subsubsection{Isoliquiritigenin:}

Natural flavonoid Isoliquiritigenin (ILG) is a chemical substance extracted from the roots of the Glycyrrhiza species. It inhibits the activation and phosphorylation of NF- $\mathrm{KB}$ in LPS stimulated macrophages that subsequently causes the down-regulation of the pro-inflammatory molecules, including PGE2, TNF- $\alpha$, and IL-6 (217).

Also, in endothelial cells treated with TNF- $\alpha$, ILG can inhibit the transcription and expression of the adhesion molecules like VCAM-1 and E-selectin (218). ILG is effective against the influenza virus as well. It activates the expression of antioxidant enzymes via the transcription factors for $\operatorname{Nrf} 2(219,220)$. A recent study assessed the effects of ILG on improving inflammation and viral replication in human bronchial epithelial cells (187).

It is found that ILG inhibits the release of inflammatory factors from infected cells. This antiinflammatory function is achieved through the activation of the PPARY signaling pathway (221). ILG also reduced the expression of cytokine proteins, and subsequently, inflammation in the patient's lung tissue $(222,223)$. Moreover, by using ILG, the inflammatory cells, especially T cells infiltration, has been attenuated in mice. Based on these findings and the anti-inflammatory effects of ILG in the lung cells, this substance might effectively treat COVID-19 infections.

\subsubsection{Lianhua Qingwen:}

Lianhua Qingwen (LHQW) is a traditional Chinese medicine with anti-inflammatory and immune regulatory effects $(224,225)$. LHQW suppressed IL-8, IL-6, TNF- $\alpha$, CCL-2, CXCL-10, MCP-1, and NF$\kappa \mathrm{B}$ activation in a dose-proportional manner. LHQW suppresses many factors that contribute to worsening a viral infection. Therefore it has some antiviral functions $(188,224,226)$. 
A recent in vivo study evaluated the effects of LHQW on A-type influenza. Phosphorylation of NF-kB, expression of IL-8, IL-6, TNF- $\alpha$, CXCL10, and MCP-1 was found to be suppressed by this substance (188). Also, the antiviral activity of LHQW against SARS-CoV-2 has been reported in vitro. Data suggest a significant reduction of IL-6, TNF- $\alpha$, CCL-2, CXCL-10, and MCP-1 expression following LHQW. The SARS-CoV-2 replication was inhibited as well (227).

Research performed by Liang Dong et al., about treatment with LHQW in acute exacerbation of chronic obstructive pulmonary disease showed a reduction in the expression of IL-8, IL-17, IL-23, and TNF- $\alpha$ after the treatment in the patients (190). In another research, LHQW down-regulated the MCP-1 serum levels in LPS-induced ALI in mice (191). Based on these and other studies, the anti-inflammatory properties of LHQW might help treat COVID-19 infections $(228,229)$.

\subsubsection{Magnoflorine:}

Magnoflorine (MAG) is an alkaloid that is extracted from Tinospora species. It has antioxidative, antianxiety, anticancer, anti-cancer and anti-inflammatory properties (230). In Chinese herbal medicine, it is used to treat coughs, headaches, allergic diseases, and psychological disorders like depression. It also helps to lower the blood pressure (231-234).

In general, MAG inhibits the expression of IL-1 $\beta$, TNF- $\alpha$, IL-6, phosphorylation of p65, p38, ERK and $\mathrm{I} \kappa \mathrm{B} \alpha$. Besides, it suppresses NF- $\kappa \mathrm{B}$, related factors and cytokines. A study using LPS-induced models found that MAG inhibits the TLR4/NF- $\mathrm{kB}$ signaling pathway in vitro and also decreases the expression of IL-1 $\beta$, IL-6, IL-8, and TNF- $\alpha$ (192).

A recent study evaluated the NF- $\mathrm{BB}$ signaling pathway activity in the macrophages in vitro. Findings showed that TNF- $\alpha$, IL-1 $\beta$, and PGE2 were upregulated by MAG (193). Another recent in vivo study on mice demonstrated the anti-inflammatory effects of MAG in LPS induced acute lung injury. They demonstrated that MAG inhibits the TLR4/NF- $\mathrm{KB}$ signaling pathway and also reduces the production of the MAPK and NF- $\mathrm{BB}$ signaling pathway-related proteins as well as pro-inflammatory cytokines like IL$1 \beta$, TNF- $\alpha$, and IL-6 (194). Therefore, due to the promising anti-inflammatory properties of MAG, it might prove valuable in the treatment of COVID-19 infections.

\subsubsection{Ma Huang Tang:}

Ma Huang Tang (MHT) is a classic Chinese herbal medicine usually used for upper respiratory tract infections like influenza, bronchitis, asthma, and fever and headaches $(235,236)$. Some investigations have shown that MHT decreases lung index, TNF- $\alpha$, IL-4, IL-5, IL-1 $\beta$, CD3+/CD8+ T cell rates, protein expression of TLR4, TLR7, MyD88, and NF- $\kappa B$. It also increases IL-10, IFN- $\gamma$, IL-2, and CD4+/CD8+ T cell rates.

Anti-inflammatory properties of MHT are related to inhibiting the MYD88-dependent pathway of TLR4 $(196,237)$. Three recent studies performed by Wenyang Wei et al., evaluated the effects of MHT in Influenza A-induced viral infections. In vitro studies showed some effective antiviral functions for MHT. The results also represented a reduction of IL-4, IL-5, and an increase in IL-2, IFN- $\gamma$ due to the inhibition of the TLR4 pathway, MYD88-dependently (237). Another study investigated the effects of MHT in Influenza A-induced viral infections in vitro and in vivo. They found a reduction in IL- $1 \beta$, TNF- $\alpha$, and NF-кB (196).

In another investigation on Influenza-infected cells, a reduction of TLR4, TLR7, MYD88, and TRAF6 expression was found. The mechanism of this reduction was the inhibition of the TLR4 signaling pathway by MHT. Based on these studies and the reported anti-inflammatory properties of MHT, it might help treat COVID-19 infections (237). 


\section{Conclusion}

In conclusion, sevoflurane, quercetin, resveratrol, curcumin, KIOM-C, bergenin, garcinia kola, shenfu, piperlongumine, wogonin, oroxylin, plantamajoside, naringin, ginseng, kaempferol, allium sativum L, illicium henryi, isoliquiritigenin, lianhua Qingwen, magnoflorine and ma Huang Tang were all found to be effective to inhibit NF-kB pathway which in turn reduces the probability of cytokine storms. Therefore, these natural products could prove helpful in the control of COVID-19 infections. However, more extensive comprehensive studies and clinical trials will be required to demonstrate these effects beyond doubt, especially if they are to be used as a form of approved treatment. 
Table 1. In vivo studies investigating the role of NF- $\kappa B$ pathway to inhibit cytokine storm

\begin{tabular}{|c|c|c|c|c|c|}
\hline \multirow{2}{*}{ Studies } & \multirow{2}{*}{ Natural Product } & \multirow{2}{*}{ Dose } & \multirow{2}{*}{ Inflammatory Agent } & \multicolumn{2}{|c|}{ Effect } \\
\hline & & & & Signaling Pathway & Cytokines \\
\hline \multirow{2}{*}{$(54)$} & \multirow{3}{*}{ Sevoflurane } & $3.4 \%$ & LPS & Induce PGE2 & Increase IL-10 \& Reduce IFN- $\gamma$ \\
\hline & & \multirow[b]{2}{*}{$3 \%$} & \multirow{2}{*}{ LPS } & \multirow{2}{*}{$\begin{array}{l}\text { Blocking miR-27a /TLR4/ MyD88/NF- } \\
\kappa \mathrm{KB}\end{array}$} & \multirow{2}{*}{ Decrease TNF- $\alpha,(\mathrm{IL})^{-}-1 \beta \&$ IL- 6} \\
\hline$(84)$ & & & & & \\
\hline$(24)$ & Quercetin & $2 \mathrm{mg} / \mathrm{ml}$ and $4 \mathrm{mg} / \mathrm{ml}$ & $\begin{array}{l}\text { Radiation-induced lung injury } \\
\text { (RILI) }\end{array}$ & $\begin{array}{c}\text { Decrease NF-kB/MAPK \& JNK/SAPK, } \\
\text { p38 and p44/p42 }\end{array}$ & Decrease TNF- $\alpha$, (IL) $-1 \beta$ IL- $8 \&$ IL- 6 \\
\hline$(84)$ & \multirow{2}{*}{ Resveratrol } & $100 \mathrm{mg} / \mathrm{kg}$ & Spinal cord injury & 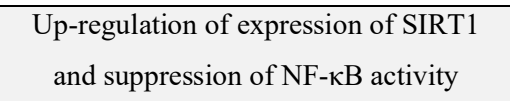 & Increase IL-10 \& Reduce IL- $1 \&$ IL- 6 \\
\hline (73) & & $100 \mathrm{mg} / \mathrm{kg}$ & Staphylococcal enterotoxin B & $\begin{array}{l}\text { up-regulation of expression of SIRT1 and } \\
\text { suppression of NF- } \mathrm{kB} \text { activity }\end{array}$ & Increase cd $11 \mathrm{~b}+$ and gr $1+$ \\
\hline$(81)$ & \multirow{4}{*}{ Curcumin } & $1 \mathrm{mg} / \mathrm{kg}$ and $5 \mathrm{mg} / \mathrm{kg}$ & $\begin{array}{c}\text { Intestinal ischemia-reperfusion } \\
\text { injury (IIR) }\end{array}$ & Inhibiting NF-kB & Decrease IL-6 \\
\hline$(83)$ & & 200 mg/kg, p.o. & $\mathrm{CCl} 4$ & inhibiting NF-KB & Decrease TNF- $\alpha$, IL-1 $\beta$, and IL-6 \\
\hline$(84)$ & & $70 \mu \mathrm{M} / \mathrm{kg}$ & Cardiac Ischemia/Reperfusion & inhibiting NF- $\mathrm{kB}$ & Decrease IL- 8, IL-10 \&TNF- $\alpha$ \\
\hline$(85)$ & & $15 \mu \mathrm{M}$ & Prostate cancer metastasis & $\begin{array}{l}\text { inhibition loop between NFKB and } \\
\qquad \text { CXCL1/-2 }\end{array}$ & Decrease CXCL1 and -2 \\
\hline$(84)$ & KIOM-C & $150 \mu \mathrm{M}(0.163 \mathrm{mg} / \mathrm{L})$ & H1N1 flu & IFN type I & $\begin{array}{c}\text { Increases } \\
\text { TNF- } \alpha \& \text { decrease IL-6, IL-10 MCP-1 }\end{array}$ \\
\hline$(238)$ & \multirow{2}{*}{ Kolaviron } & $15,25,50$ and $100 \mu \mathrm{M}$ & LPS & $\begin{array}{c}\text { Inhibition ERK1/2, NF- } \kappa B, p 38, \text { Akt, p- } \\
\text { c-JUN and JNK }\end{array}$ & Inhibition of IL-6 secretion \\
\hline$(84)$ & & $400 \mathrm{mg} / \mathrm{kg}$ & A/H3N2/ Pert/16.09 & $\begin{array}{c}\text { Reduces } \\
\text { pulmonary expression of NF- } \mathrm{kB}\end{array}$ & $\begin{array}{c}\text { Reduces } \\
\text { IL-1b, RANTES, IL-10, MCP-1 }\end{array}$ \\
\hline (7) & \multirow{4}{*}{ Shenfu } & $\begin{array}{c}0.1 \mathrm{mg} \text { aconitine and } 0.5 \\
\text { mg ginsenoside per }\end{array}$ & LPS & Abolished NF-kB & Decreased IL-6 \\
\hline \multirow{2}{*}{$(239)$} & & milliliter & & & \\
\hline & & $1 \mathrm{mg} / \mathrm{mL}$ Panax ginseng & \multirow{2}{*}{ Epinephrine } & \multirow{2}{*}{ Ischemia accompanying cardiac arrest } & \multirow[t]{2}{*}{ Decreased IL-6, IL-8 and TNF- $\alpha$} \\
\hline (84) & & C. A. Mey. and $2 \mathrm{mg} / \mathrm{mL}$ & & & \\
\hline
\end{tabular}




\begin{tabular}{|c|c|c|c|c|c|}
\hline & & $\begin{array}{l}\text { Radix Aconitum } \\
\text { Carmichaeli. }\end{array}$ & & & $\begin{array}{c}\text { Decreased C3, C4 and C5b-9 } \\
\text { Increased IL-4 } \\
\text { and IL-10 }\end{array}$ \\
\hline & & $10,100 \mathrm{mg} / \mathrm{kg}$ & LPS & Reduced NF-kB & Inhibited TNF- $\alpha$ and IL-6 \\
\hline (84) & \multirow{3}{*}{ Piperlongumine } & $10 \mathrm{mg} / \mathrm{kg}$ & Ovalbumin & Inhibiting $N F-\kappa B$ & $\begin{array}{l}\text { Reduced the serum IgE level, } \\
\text { TNF- } \alpha \text { and IL- } 6\end{array}$ \\
\hline (129) & & $10-30 \mathrm{mg} / \mathrm{kg}$ & LPS & Inhibited NF-kB signaling cascade & $\begin{array}{c}\text { Reduced IL-1 } \beta, \text { IL- } \\
6, \text { TNF- } \alpha, \text { IL-17, IL-22, and } \\
\text { (TGF)- } \beta\end{array}$ \\
\hline (84) & & $\begin{array}{c}50 \\
\text { and } 100 \mu \mathrm{M}\end{array}$ & LPS & $\begin{array}{c}\text { Inhibition of NF-kB-Akt-AP-1- } \\
\text { p38/ERK1/2-JNK MAPK signaling } \\
\text { pathways }\end{array}$ & Reduced IL- 6 \\
\hline (69) & \multirow{2}{*}{ Oroxylin A } & $15 \mathrm{mg} / \mathrm{KG}$ & LPS & $\begin{array}{l}\text { Abolished } \\
\text { NF-kB }\end{array}$ & Blockade of TNF, NO, HMGB1 \\
\hline (84) & & 15,30 , and $60 \mathrm{mg} / \mathrm{kg}$ & Ovalbumin & $\begin{array}{l}\text { Inhibited } \\
\text { NF-kB }\end{array}$ & Reduced IL-4, IL-5, IL-13, and serum IgE \\
\hline (156) & Plantamajoside & 25,50 and $100 \mathrm{mg} / \mathrm{kg}$ & LPS & Inhibition of the NF- $\mathrm{KB}$ and MAPK & $\begin{array}{l}\text { Reduction in IL- } 1 \beta \text {, IL- } 6 \text {, and TNF- } \alpha \text { and } \\
\text { elevation in the IL-10 }\end{array}$ \\
\hline (84) & \multirow[t]{2}{*}{ Naringin } & $\begin{array}{c}30 \text { or } 60 \mathrm{mg} / \\
\mathrm{kg}\end{array}$ & LPS & Inhibition of NF- $\mathrm{kB}$ & $\begin{array}{c}\text { Decreased IL-6, TNF- } \alpha \text {, and HMGB-1 } \\
\text { Elevated IL-10 }\end{array}$ \\
\hline (178) & & $100 \mathrm{mg} / \mathrm{kg}$ & Gentamycin & Inhibition of NF-kB & Decreased TNF- $\alpha$ and IL-6 \\
\hline (84) & Ginsenoside & $20 \mathrm{mg} / \mathrm{kg}$ & $\begin{array}{c}\text { LPS } \\
\text { PG }\end{array}$ & Blockage of binding of LPS to TLR4 & Inhibition of IL- $1 \beta$, NF- $\mathrm{kB}$ and TNF \\
\hline (183) & Kaempferol & $100 \mathrm{mg} / \mathrm{kg}$ & LPS & $\begin{array}{l}\text { Blockage of MAPKs and NF-kB } \\
\text { signaling pathway }\end{array}$ & $\begin{array}{c}\text { Decreasing inflammatory factors like TNF- } \alpha \text {, } \\
\text { IL-1 } 1 \beta \text {, and IL-6 }\end{array}$ \\
\hline (84) & $\begin{array}{c}\text { Allium sativum } \\
\quad L .\end{array}$ & $15 \mathrm{mg} / \mathrm{kg}$ & LPS & $\begin{array}{c}\text { Blockage of cytokine storm/ enhancing } \\
\text { microbial killing }\end{array}$ & Inhibition of HL- $1 \beta$ and TNF- $\alpha$ \\
\hline (185) & \multirow{2}{*}{ Illicium henryi } & $1.25-5 \mathrm{mg} / \mathrm{kg}$ & LPS & $\begin{array}{c}\text { Suppression of NF-kB/TLR4 pathway/ } \\
\text { upregulating Nrf2 }\end{array}$ & $\begin{array}{c}\text { Decreasing inflammatory factors like TNF- } \alpha \text {, } \\
\text { IL-1 } 1 \beta \text {, and IL-6 }\end{array}$ \\
\hline (84) & & $1.25-5 \mathrm{mg} / \mathrm{kg}$ & LPS & Suppression of NF-kB/TLR4 pathway/ & Decreasing inflammatory factors like TNF- $\alpha$, \\
\hline
\end{tabular}




\begin{tabular}{|c|c|c|c|c|c|}
\hline & & & & upregulating Nrf2 & IL-1 $1 \beta$, and IL-6 \\
\hline (187) & Isoliquiritigenin & $10 \mathrm{mg} / \mathrm{kg}$ & Influenza A (H1N1 strain) & $\begin{array}{c}\text { Activation of the peroxisome } \\
\text { proliferator-activated receptor-gamma } \\
\text { (PPARY) pathway/ inhibits activation of } \\
\text { NF-kB }\end{array}$ & $\begin{array}{l}\text { Decreasing inflammatory factors like TNF- } \alpha \text {, } \\
\text { PGE2, and IL-6 }\end{array}$ \\
\hline (84) & \multirow{3}{*}{ Lianhuaqingwen } & $0.35-2 \mathrm{mg} / \mathrm{ml}$ & Influenza A & Suppression of NF-kB activation & $\begin{array}{l}\text { Reduction of IL-8, IL-6, TNF- } \alpha \text {, IP-10, and } \\
\text { MCP-1 }\end{array}$ \\
\hline (190) & & & AECOPD patients & $\begin{array}{l}\text { Suppression of IL-8 and TNF- } \alpha \\
\text { (important mediators in AECOPD) }\end{array}$ & Reduction of IL- 8 , IL-17, IL-23, and TNF- $\alpha$ \\
\hline (84) & & $300-1200 \mathrm{mg} / \mathrm{kg}$ & LPS & Decreasing MCP-1 serum level & Reduction of TNF- $\alpha$ \\
\hline (194) & Magnoflorine & 5,10 , and $20 \mathrm{mg} / \mathrm{kg}$ & LPS & $\begin{array}{l}\text { Inhibition of the TLR4- NF-kB signaling } \\
\text { pathway }\end{array}$ & Reduction of IL-1 $\beta$, TNF- $\alpha$, IL-6 \\
\hline
\end{tabular}


Table 2. In vitro studies investigating the role of the NF- $\mathrm{kB}$ pathway to inhibit cytokine storm

\begin{tabular}{|c|c|c|c|c|c|}
\hline \multirow{2}{*}{ Studies } & \multirow{2}{*}{ Natural Product } & \multirow{2}{*}{ Dose } & \multirow{2}{*}{ Inflammatory Agent } & \multicolumn{2}{|c|}{ Effect } \\
\hline & & & & Signaling Pathway & Cytokines \\
\hline (66) & \multirow{3}{*}{ Quercetin } & $>50 \mu \mathrm{M}$ & $\begin{array}{c}\text { Polyinosinic- } \\
\text { Polycytidylic Acid }\end{array}$ & Blocking calcium-STAT & $\begin{array}{l}\text { Decrease IL-6, MCP-1, IP-10, RANTES, GM- } \\
\text { CSF, G-CSF, TNF- } \alpha \text {, LIF, LIX, and VEGF }\end{array}$ \\
\hline (84) & & $5-20 \mu \mathrm{M} 98 \%$ & LPS & $\begin{array}{c}\text { Inhibit tyrosine-phosphorylated } \\
\text { phosphatidylinositol 3-kinase and myeloid } \\
\text { differentiation factor-88 association and } \\
\text { inhibit MAPK/AP-1 and IKK/NF-кB }\end{array}$ & Decrease TNF- $\alpha$, (IL)- $1 \beta$ IL- 6 \& GM-CSF \\
\hline (62) & & $2.5-20 \mu \mathrm{M}$ & $(\mathrm{IL})-1 \beta$ & Blocking of MAPK and NF- $\mathrm{kB}$ & Decrease IL-8, IL-6, MCP-1 \&TNF- $\alpha$ \\
\hline (84) & Resveratrol & $1 \mathrm{mg} / \mathrm{mL}$ & LPS & $\begin{array}{l}\text { Blocking MAPK, NF-kB \& TLR negative } \\
\text { regulator }\end{array}$ & $\begin{array}{c}\text { Decrease TNF- } \alpha, \text { IL-6, IL-1 } \beta \text {, and IL-12p70, } \\
\text { IRAK-1 }\end{array}$ \\
\hline$(101)$ & Bergenin & $\begin{array}{l}20,50 \mathrm{mg} / \mathrm{kg} \\
\text { with the purity }>98 \%\end{array}$ & $\begin{array}{l}\text { Dextran sulfate } \\
\text { sodium (DSS) }\end{array}$ & $\begin{array}{c}\text { Regulating PPAR- } \gamma / \text { SIRT1/NF-kB-p65 } \\
\text { pathway }\end{array}$ & Reduces TNF- $\alpha$ and IL- 6 expression \\
\hline (84) & \multirow[b]{2}{*}{ Piperlongumine } & NA & NA & Attenuate NF-kB & Reduced IL-6, IL-8, MMP-9, and ICAM-1 \\
\hline (121) & & $3 \mu \mathrm{M}$ & LPS & NA & NA \\
\hline (84) & \multirow{3}{*}{ Wogonin } & $0-50 \mu \mathrm{M}$ & LPS & TLR4/NF- $\mathrm{kB}$ signaling pathway & $\begin{array}{c}\text { Inhibition of IL-1 } \beta, \text { IL- } 6, \text { IL- } 8, \text { COX-2, } \\
\text { iNOS, and TNF- } \alpha\end{array}$ \\
\hline$(138)$ & & $0-100 \mu \mathrm{M}$ & LPS & $\begin{array}{c}\text { TLR4-MyD88-TAK1-Mediated NF-kB and } \\
\text { MAPK } \\
\text { Signaling Pathway }\end{array}$ & $\begin{array}{l}\text { Inhibition of expressions of iNOS, COX-2, } \\
\text { TNF-a, IL-1b, and IL-6 }\end{array}$ \\
\hline (84) & & $\begin{array}{c}10 \text { and } 50 \\
\mu \mathrm{M}\end{array}$ & LPS & $\begin{array}{l}\text { TLR4-MyD88-TAK1-mediated } \\
\text { NF-кB pathway }\end{array}$ & $\begin{array}{c}\text { Decreased IL-1b, IL-6, IL-8, COX-2, and } \\
\text { iNOS }\end{array}$ \\
\hline$(145)$ & Oroxylin $A$ & $100 \mu \mathrm{M}$ & LPS & $\begin{array}{l}\text { Inhibited } \\
\text { NF-кB }\end{array}$ & Reduced IL-6 \\
\hline
\end{tabular}




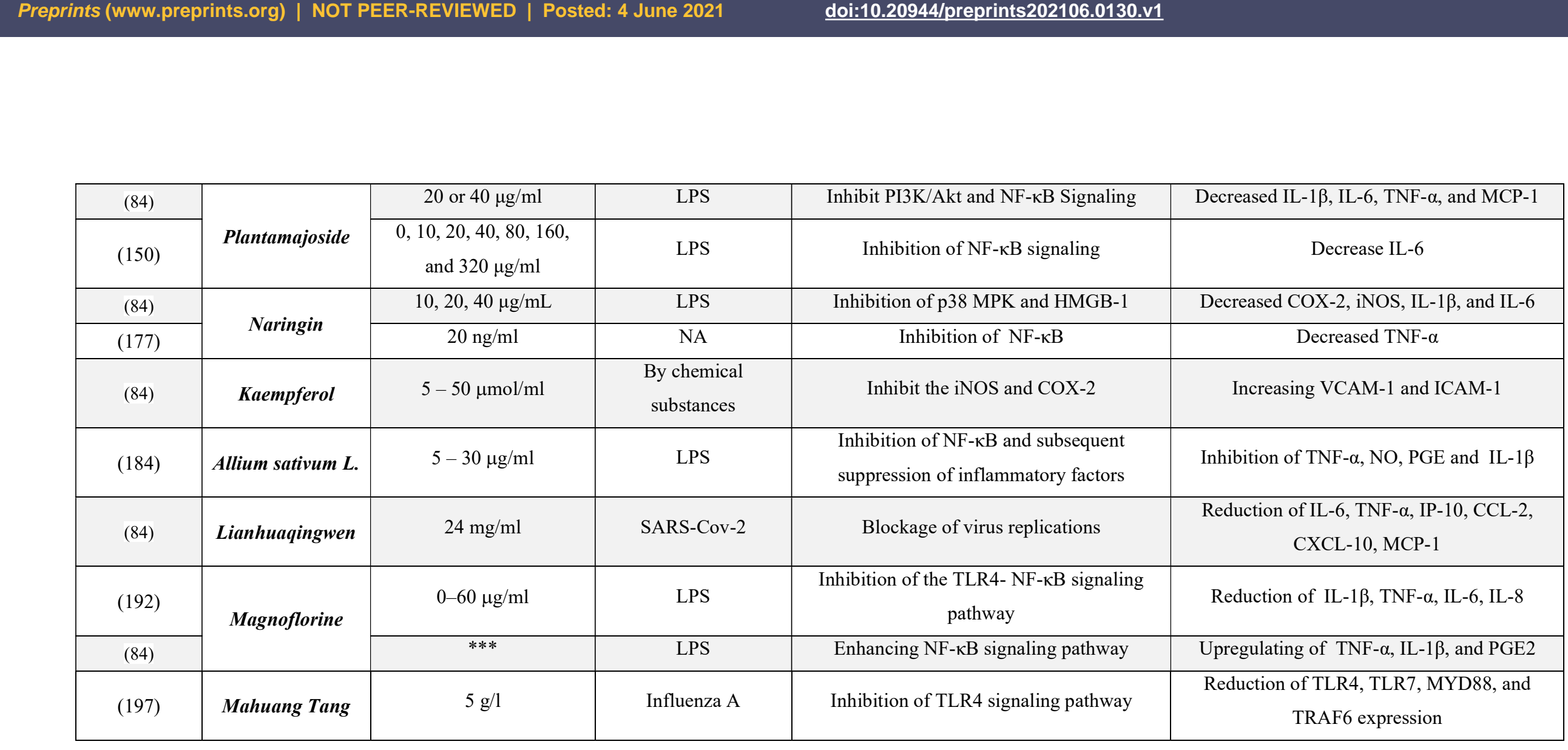


Table 3. Studies investigating role of NF-kB pathway to inhibit cytokine storm through both in vivo and in vitro experiments

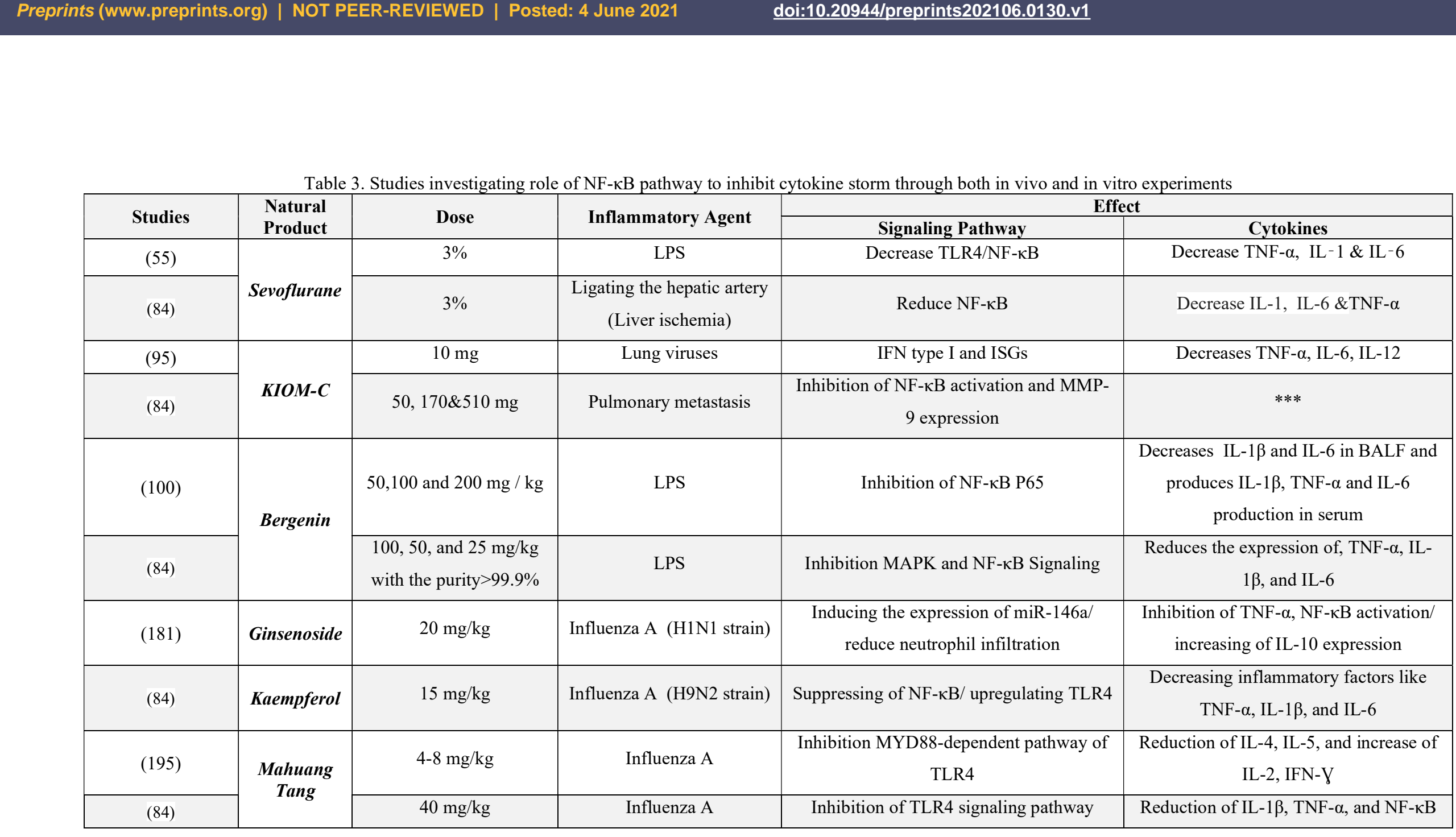




\section{Abbreviations}

3-CLpro: 3-chymotrypsin-like protease

ACE-2: Angiotensin converting enzyme 2

AGE's: Advanced glycation end products

AHR: Airway hyperresponsiveness

Akt: Protein kinase B (PKB)

ALI: Acute lung injury

AP-1: Activator Protein1

APCs: Antigen-presenting cells

ARDS: Acute respiratory distress syndrome

ATF2: Activating transcription factor 2

BALF: Bronchoalveolar lavage fluid

CCL-2: $\mathrm{C}-\mathrm{C}$ motif chemokine ligand 2

COX-2: Cyclooxygenase-2

CREB: cAMP-response element binding protein

CXCL-10: C-X-C motif chemokine ligand 10

DAMP: Damage-associated molecular pattern

ERK: Extracellular signal-regulated kinase

ERK1/2: Mitogen-activated protein kinase 1/2

G-CSF: Granulocyte colony-stimulating factor

GM-CSF: Granulocyte-macrophage colony-stimulating factor

HBV: Hepatitis B virus

HMGB1: High-mobility group box 1

HO-1: Heme oxygenase-1

ICAM-1: Intercellular Adhesion Molecule 1

IFN: Interferon

IFNAR: Interferon $\alpha / \beta$ receptor

IFR-3: Interferon regulatory factor 3

IKK $\beta$ : IkB-kinase

IL-1 $\beta$ : Interleukin 1 beta

IL-6: Interleukin-6

iNOS: Inducible nitric oxide synthase 
IRAK-1: Interleukin-1 receptor-associated kinase 1

ISGs: IFN-stimulated genes

ISRE: IFN-stimulated response element

IкB $\alpha$ : Inhibitory kappa B

LIF: Leukemia inhibitory factor

LIX: Phytoclock1

$(\mathrm{IKK}) \alpha / \beta$ : Nuclear factor $\kappa-\mathrm{B}$ kinase

MAPK: Mitogen-activated protein kinase

MCP-1: Monocyte Chemoattractant Protein-1

MDA: Malondialdehyde

MDSCs: Myeloid-derived suppressor cells

MMP: Matrix metalloproteinase

MMP-9: Matrix metallopeptidase 9

MPO: Myeloperoxidase

Myd88: Myeloid differentiation factor 88

NIK: NF- $\kappa B$ inducing kinase

NF-kB: Nuclear factor kappa-light-chain-enhancer of activated B cells

NO: Nitric Oxide

Nrf2: Nuclear factor erythroid 2 related factors 2

PCVAD: Porcine circovirus-associated disease

PMA: Phorbol myristate acetate

RANTES: Regulated upon activation, normal $\mathrm{T}$ cell expressed and presumably secreted

Rg: red ginseng

RIP: Receptor interacting protein-1

RdRp: RNA-dependent RNA polymerase

RP8: A/Puerto Rico/8/34

ROS: Reactive oxygen species

p65: Protein 65

p38: Protein 38

PAMPs: Pathogen-associated molecular patterns

PGE: Prostaglandin E

PGE2: Prostaglandin E2 
PI3K: Phosphatidylinositol 3-kinase

PLpro: Papain-like protease

PPAR- $\gamma$ : Peroxisome proliferator-activated receptor-gamma

SMFM: Methyl 3-formyl-4methykpentanoate

SOD: Superoxide dismutase

STAT1: Signal transducer and activator of transcription 1

TAK1: Transforming growth factor- $\beta$ activated kinase 1

TBK1: TANK-binding kinase 1

TLR-3: Toll-like receptor-3

TNBS-induced colitis: 2,4,6-trinitrobenzenesulfonic acid-induced colitis

TNF- $\alpha$ : Tumor necrosis factor-alpha

TRAF2: TNF receptor-associated factor-2

TRAF6: Tumor necrosis factor receptor-associated factor 6

VEGF: Vascular endothelial growth factor

\section{References:}

1. Maier HJ, Bickerton E, Britton P. Coronaviruses: methods and protocols: Springer Berlin; 2015.

2. Li C, Yang Y, Ren L. Genetic evolution analysis of 2019 novel coronavirus and coronavirus from other species. Infection, Genetics and Evolution. 2020:104285.

3. Liu R, Luo J, Li J, Ma Q, Sun J, Li Y, et al. Protective mechanisms of sevoflurane against one-lung ventilation-induced acute lung injury: role of cyclooxygenase-2 and 5-lipoxygenase pathways. Nan Fang Yi Ke Da Xue Xue Bao. 2013;33(5):625-30.

4. Channappanavar R, Perlman S, editors. Pathogenic human coronavirus infections: causes and consequences of cytokine storm and immunopathology. Seminars in immunopathology; 2017: Springer.

5. Gilmore TD. The Rel/NF- $\quad$ B signal transduction pathway: introduction. Oncogene. 1999;18(49):6842-

4.

6. Standiford TJ, Ward PA. Therapeutic targeting of acute lung injury and acute respiratory distress syndrome. Translational Research. 2016;167(1):183-91.

7. Liu X, Ai F, Li H, Xu Q, Mei L, Miao J, et al. Anti-Inflammatory Effects of Shenfu Injection against Acute Lung Injury through Inhibiting HMGB1-NF-кB Pathway in a Rat Model of Endotoxin Shock. EvidenceBased Complementary and Alternative Medicine. 2019;2019.

8. Meng L, Li L, Lu S, Li K, Su Z, Wang Y, et al. The protective effect of dexmedetomidine on LPSinduced acute lung injury through the HMGB1-mediated TLR4/NF- $\mathrm{KB}$ and PI3K/Akt/mTOR pathways. Molecular immunology. 2018;94:7-17.

9. PP G, Geneva. Organization WH. WHO handbook for guideline development [Internet] https://extranet.who.int/iris/restricted/handle/10665/145714 [2nd ed:[

10. Khozeimeh F, Sharifrazi D, Izadi NH, Joloudari JH, Shoeibi A, Alizadehsani R, et al. CNN AE: Convolution Neural Network combined with Autoencoder approach to detect survival chance of COVID 19 patients. arXiv preprint arXiv:210408954. 2021.

11. Sharifrazi D, Alizadehsani R, Roshanzamir M, Joloudari JH, Shoeibi A, Jafari M, et al. Fusion of convolution neural network, support vector machine and Sobel filter for accurate detection of COVID-19 patients using X-ray images. Biomedical Signal Processing and Control. 2021;68:102622. 
12. Alizadehsani R, Alizadeh Sani Z, Behjati M, Roshanzamir Z, Hussain S, Abedini N, et al. Risk factors prediction, clinical outcomes, and mortality in COVID-19 patients. Journal of Medical Virology. 2021;93(4):2307-20.

13. Eskandarian R, Sani ZA, Behjati M, Zahmatkesh M, Haddadi A, Kakhi K, et al. Identification of clinical features associated with mortality in COVID-19 patients. medRxiv. 2021.

14. Vankadari N, Wilce JA. Emerging WuHan (COVID-19) coronavirus: glycan shield and structure prediction of spike glycoprotein and its interaction with human CD26. Emerging Microbes \& Infections. 2020;9(1):601-4.

15. Shoeibi A, Khodatars M, Alizadehsani R, Ghassemi N, Jafari M, Moridian P, et al. Automated detection and forecasting of covid-19 using deep learning techniques: A review. arXiv preprint arXiv:200710785. 2020.

16. Ayoobi N, Sharifrazi D, Alizadehsani R, Shoeibi A, Gorriz JM, Moosaei H, et al. Time Series Forecasting of New Cases and New Deaths Rate for COVID-19 using Deep Learning Methods. arXiv preprint arXiv:210415007. 2021.

17. Ghassemi N, Shoeibi A, Khodatars M, Heras J, Rahimi A, Zare A, et al. Automatic Diagnosis of COVID-19 from CT Images using CycleGAN and Transfer Learning. arXiv preprint arXiv:210411949. 2021.

18. Duan Y, Zhu H-L, Zhou C. Advance of promising targets and agents against 2019-nCoV in China. Drug Discovery Today. 2020.

19. Alizadehsani R, Sharifrazi D, Izadi NH, Joloudari JH, Shoeibi A, Gorriz JM, et al. Uncertainty-Aware Semi-supervised Method using Large Unlabelled and Limited Labeled COVID-19 Data. arXiv preprint arXiv:210206388. 2021.

20. Prompetchara E, Ketloy C, Palaga T. Immune responses in COVID-19 and potential vaccines: Lessons learned from SARS and MERS epidemic. Asian Pac J Allergy Immunol. 2020;38(1):1-9.

21. Dandekar AA, Perlman S. Immunopathogenesis of coronavirus infections: implications for SARS. Nature reviews immunology. 2005;5(12):917-27.

22. de Wit E, van Doremalen N, Falzarano D, Munster VJ. SARS and MERS: recent insights into emerging coronaviruses. Nature Reviews Microbiology. 2016;14(8):523.

23. Chirumbolo $\mathrm{S}$. The role of quercetin, flavonols and flavones in modulating inflammatory cell function. Inflammation \& Allergy-Drug Targets (Formerly Current Drug Targets-Inflammation \& Allergy). 2010;9(4):263-85.

24. Lee SK, Park YJ, Ko MJ, Wang Z, Lee HY, Choi YW, et al. A novel natural compound from garlic (Allium sativum L.) with therapeutic effects against experimental polymicrobial sepsis. Biochem Biophys Res Commun. 2015;464(3):774-9.

25. Heydari K, Rismantab S, Shamshirian A, Lotfi P, Shadmehri N, Houshmand P, et al. Clinical and Paraclinical Characteristics of COVID-19 patients: A systematic review and meta-analysis. medRxiv. 2020.

26. Yang X, Yu Y, Xu J, Shu H, Liu H, Wu Y, et al. Clinical course and outcomes of critically ill patients with SARS-CoV-2 pneumonia in Wuhan, China: a single-centered, retrospective, observational study. The Lancet Respiratory Medicine. 2020.

27. Kao SJ, Su CF, Liu DD, Chen HI. Endotoxin-induced acute lung injury and organ dysfunction are attenuated by pentobarbital anaesthesia. Clinical and Experimental Pharmacology and Physiology. 2007;34(56):480-7.

28. Johnson ER, Matthay MA. Acute lung injury: epidemiology, pathogenesis, and treatment. Journal of aerosol medicine and pulmonary drug delivery. 2010;23(4):243-52.

29. Okamoto M, Lee C, Oyasu R. Interleukin-6 as a paracrine and autocrine growth factor in human prostatic carcinoma cells in vitro. Cancer research. 1997;57(1):141-6.

30. Li A, Varney ML, Singh RK. Expression of interleukin 8 and its receptors in human colon carcinoma cells with different metastatic potentials. Clinical Cancer Research. 2001;7(10):3298-304.

31. Wallach D, Varfolomeev E, Malinin N, Goltsev YV, Kovalenko A, Boldin M. Tumor necrosis factor receptor and Fas signaling mechanisms. Annual review of immunology. 1999;17(1):331-67.

32. Hsu H, Xiong J, Goeddel DV. The TNF receptor 1-associated protein TRADD signals cell death and NF- $\kappa$ B activation. Cell. 1995;81(4):495-504.

33. Malinin NL, Boldin MP, Kovalenko AV, Wallach D. MAP3K-related kinase involved in NF-kB induction by TNF, CD95 and IL-1. Nature. 1997;385(6616):540-4.

34. Régnier CH, Song HY, Gao X, Goeddel DV, Cao Z, Rothe M. Identification and characterization of an IкB kinase. Cell. 1997;90(2):373-83. 
35. Ozes ON, Mayo LD, Gustin JA, Pfeffer SR, Pfeffer LM, Donner DB. NF-kB activation by tumour necrosis factor requires the Akt serine-threonine kinase. Nature. 1999;401(6748):82-5.

36. Wu AH, He L, Long W, Zhou Q, Zhu S, Wang P, et al. Novel mechanisms of herbal therapies for inhibiting HMGB1 secretion or action. Evidence-Based Complementary and Alternative Medicine. 2015;2015.

37. Zhang Y, Zhang M, Wang C, Shen A. Ketamine alleviates LPS induced lung injury by inhibiting HMGB1-RAGE level. European review for medical and pharmacological sciences. 2018;22(6):1830-6.

38. Wang H, Bloom O, Zhang M, Vishnubhakat JM, Ombrellino M, Che J, et al. HMG-1 as a late mediator of endotoxin lethality in mice. Science. 1999;285(5425):248-51.

39. Imbalzano E, Quartuccio S, Di Salvo E, Crea T, Casciaro M, Gangemi S. Association between HMGB1 and asthma: a literature review. Clinical and Molecular Allergy. 2017;15(1):12.

40. Venereau E, De Leo F, Mezzapelle R, Careccia G, Musco G, Bianchi ME. HMGB1 as biomarker and drug target. Pharmacological research. 2016;111:534-44.

41. Jiang F, Deng L, Zhang L, Cai Y, Cheung CW, Xia Z. Review of the clinical characteristics of coronavirus disease 2019 (COVID-19). Journal of General Internal Medicine. 2020:1-5.

42. Solá Gurpegui I, Cantón J, Fehr AR, Fernandez-Delgado R, Gutierrez-Alvarez FJ, Vigara G, et al. MERS-CoV 4b protein interferes with the NF-kB-dependent innate immune response during infection. 2019.

43. SALLENAVE J-M, Guillot L. Host signaling and proteolytic pathways in the resolution or the exacerbation of coronavirus (CoV-2) infection in COVID-19 disease: what therapeutic targets? 2020.

44. Nam N-H. Naturally occurring NF-kB inhibitors. Mini reviews in medicinal chemistry. 2006;6(8):945-

51.

45. Rabi FA, Al Zoubi MS, Kasasbeh GA, Salameh DM, Al-Nasser AD. SARS-CoV-2 and Coronavirus Disease 2019: what we know so far. Pathogens. 2020;9(3):231.

46. Li G, Fan Y, Lai Y, Han T, Li Z, Zhou P, et al. Coronavirus infections and immune responses. Journal of medical virology. 2020;92(4):424-32.

47. Murphy K, Weaver C. Janeway's immunobiology: Garland science; 2016.

48. Zumla A, Hui DS, Azhar EI, Memish ZA, Maeurer M. Reducing mortality from 2019-nCoV: hostdirected therapies should be an option. The Lancet. 2020;395(10224):e35-e6.

49. Totura AL, Baric RS. SARS coronavirus pathogenesis: host innate immune responses and viral antagonism of interferon. Current opinion in virology. 2012;2(3):264-75.

50. Astuti I. Severe Acute Respiratory Syndrome Coronavirus 2 (SARS-CoV-2): An overview of viral structure and host response. Diabetes \& Metabolic Syndrome: Clinical Research \& Reviews. 2020.

51. Li X, Geng M, Peng Y, Meng L, Lu S. Molecular immune pathogenesis and diagnosis of COVID-19. Journal of Pharmaceutical Analysis. 2020.

52. Chen J, Lau YF, Lamirande EW, Paddock CD, Bartlett JH, Zaki SR, et al. Cellular immune responses to severe acute respiratory syndrome coronavirus (SARS-CoV) infection in senescent BALB/c mice: CD4+ T cells are important in control of SARS-CoV infection. Journal of virology. 2010;84(3):1289-301.

53. Patel HH, Tsutsumi YM, Head BP, Niesman IR, Jennings M, Horikawa Y, et al. Mechanisms of cardiac protection from ischemia/reperfusion injury: a role for caveolae and caveolin-1. The FASEB Journal. 2007;21(7):1565-74.

54. Tang Q-F, Fang Z-Y, Shi C-H. The protective effect and mechanism of sevoflurane on LPS-induced acute lung injury in mice. American journal of translational research. 2017;9(4):1732.

55. Sun XJ, Li XQ, Wang XL, Tan WF, Wang JK. Sevoflurane inhibits nuclear factor- $\kappa B$ activation in lipopolysaccharide-induced acute inflammatory lung injury via toll-like receptor 4 signaling. PloS one. 2015;10(4).

56. Liao X, Zhou S, Zong J, Wang Z. Sevoflurane exerts protective effects on liver ischemia/reperfusion injury by regulating NFKB3 expression via miR-9-5p. Experimental and therapeutic medicine. 2019;17(4):2632-40.

57. Song S-Y, Zhou B, Yang S-M, Liu G-Z, Tian J-M, Yue X-Q. Preventive effects of sevoflurane treatment on lung inflammation in rats. Asian Pacific journal of tropical medicine. 2013;6(1):53-6.

58. Steurer M, Schläpfer M, Steurer M, Z'graggen BR, Booy C, Reyes L, et al. The volatile anaesthetic sevoflurane attenuates lipopolysaccharide-induced injury in alveolar macrophages. Clinical \& Experimental Immunology. 2009;155(2):224-30.

59. Motawi TK, Darwish HA, Hamed MA, El-Rigal NS, Naser AFA. A therapeutic insight of niacin and coenzyme Q10 against diabetic encephalopathy in rats. Molecular neurobiology. 2017;54(3):1601-11. 
60. Wang Y, Zhang X, Tian J, Liu G, Li X, Shen D. Sevoflurane alleviates LPS-induced acute lung injury via the microRNA-27a-3p/TLR4/MyD88/NF- $\mathrm{kB}$ signaling pathway. International journal of molecular medicine. 2019;44(2):479-90.

61. Granado-Serrano AB, Martín MÁ, Bravo L, Goya L, Ramos S. Quercetin attenuates TNF-induced inflammation in hepatic cells by inhibiting the NF-kB pathway. Nutrition and cancer. 2012;64(4):588-98.

62. Cheng S-C, Huang W-C, S Pang J-H, Wu Y-H, Cheng C-Y. Quercetin Inhibits the Production of IL-1 $\beta-$ Induced Inflammatory Cytokines and Chemokines in ARPE-19 Cells via the MAPK and NF- $\kappa B$ Signaling Pathways. International journal of molecular sciences. 2019;20(12):2957.

63. Wei X, Meng X, Yuan Y, Shen F, Li C, Yang J. Quercetin exerts cardiovascular protective effects in LPS-induced dysfunction in vivo by regulating inflammatory cytokine expression, NF- $\mathrm{kB}$ phosphorylation, and caspase activity. Molecular and cellular biochemistry. 2018;446(1-2):43-52.

64. Peng Z, Gong X, Yang Y, Huang L, Zhang Q, Zhang P, et al. Hepatoprotective effect of quercetin against LPS/d-GalN induced acute liver injury in mice by inhibiting the IKK/NF- $\kappa B$ and MAPK signal pathways. International immunopharmacology. 2017;52:281-9.

65. Endale M, Park S-C, Kim S, Kim S-H, Yang Y, Cho JY, et al. Quercetin disrupts tyrosinephosphorylated phosphatidylinositol 3-kinase and myeloid differentiation factor-88 association, and inhibits MAPK/AP-1 and IKK/NF-KB-induced inflammatory mediators production in RAW 264.7 cells. Immunobiology. 2013;218(12):1452-67.

66. Kim YJ, Park W. Anti-inflammatory effect of Quercetin on RAW 264.7 mouse macrophages induced with Polyinosinic-Polycytidylic acid. Molecules. 2016;21(4):450.

67. Pan M-H, Lai C-S, Dushenkov S, Ho C-T. Modulation of inflammatory genes by natural dietary bioactive compounds. Journal of agricultural and food chemistry. 2009;57(11):4467-77.

68. Vicentini FT, He T, Shao Y, Fonseca MJ, Verri Jr WA, Fisher GJ, et al. Quercetin inhibits UV irradiation-induced inflammatory cytokine production in primary human keratinocytes by suppressing NF- $\mathrm{kB}$ pathway. Journal of dermatological science. 2011;61(3):162-8.

69. Ulrich S, Wolter F, Stein JM. Molecular mechanisms of the chemopreventive effects of resveratrol and its analogs in carcinogenesis. Molecular nutrition \& food research. 2005;49(5):452-61.

70. Bellaver B, Souza DG, Souza DO, Quincozes-Santos A. Resveratrol increases antioxidant defenses and decreases proinflammatory cytokines in hippocampal astrocyte cultures from newborn, adult and aged Wistar rats. Toxicology in Vitro. 2014;28(4):479-84.

71. Lee-Chang C, Bodogai M, Martin-Montalvo A, Wejksza K, Sanghvi M, Moaddel R, et al. Inhibition of breast cancer metastasis by resveratrol-mediated inactivation of tumor-evoked regulatory B cells. The Journal of Immunology. 2013;191(8):4141-51.

72. Cullberg KB, Olholm J, Paulsen SK, Foldager CB, Lind M, Richelsen B, et al. Resveratrol has inhibitory effects on the hypoxia-induced inflammation and angiogenesis in human adipose tissue in vitro. European Journal of Pharmaceutical Sciences. 2013;49(2):251-7.

73. Rieder SA, Nagarkatti P, Nagarkatti M. Multiple anti-inflammatory pathways triggered by resveratrol lead to amelioration of staphylococcal enterotoxin B-induced lung injury. British journal of pharmacology. 2012;167(6):1244-58.

74. Wright B. Forging a modern generation of polyphenol-based therapeutics. British journal of pharmacology. 2013;169(4):844-7.

75. Liu J, Yi L, Xiang Z, Zhong J, Zhang H, Sun T. Resveratrol attenuates spinal cord injury-induced inflammatory damage in rat lungs. International journal of clinical and experimental pathology. 2015;8(2):1237.

76. Kim WS, Kim K, Byun E-B, Song H-Y, Han JM, Park WY, et al. RM, a novel resveratrol derivative, attenuates inflammatory responses induced by lipopolysaccharide via selectively increasing the Tollip protein in macrophages: A partial mechanism with therapeutic potential in an inflammatory setting. International Immunopharmacology. 2020;78:106072.

77. Okudan N, Belviranlı M, Gökbel H, Öz M, Kumak A. Protective effects of curcumin supplementation on intestinal ischemia reperfusion injury. Phytomedicine. 2013;20(10):844-8.

78. Guzel A, Kanter M, Guzel A, Yucel AF, Erboga M. Protective effect of curcumin on acute lung injury induced by intestinal ischaemia/reperfusion. Toxicology and industrial health. 2013;29(7):633-42.

79. Nazari QA, Takada-Takatori Y, Hashimoto T, Imaizumi A, Izumi Y, Akaike A, et al. Potential protective effect of highly bioavailable curcumin on an oxidative stress model induced by microinjection of sodium nitroprusside in mice brain. Food \& function. 2014;5(5):984-9. 
80. Goel A, Kunnumakkara AB, Aggarwal BB. Curcumin as "Curecumin": from kitchen to clinic. Biochemical pharmacology. 2008;75(4):787-809.

81. Fan Z, Yao J, Li Y, Hu X, Shao H, Tian X. Anti-inflammatory and antioxidant effects of curcumin on acute lung injury in a rodent model of intestinal ischemia reperfusion by inhibiting the pathway of NF-Kb. International journal of clinical and experimental pathology. 2015;8(4):3451.

82. Ganjali S, Sahebkar A, Mahdipour E, Jamialahmadi K, Torabi S, Akhlaghi S, et al. Investigation of the effects of curcumin on serum cytokines in obese individuals: a randomized controlled trial. The Scientific World Journal. 2014;2014.

83. Reyes-Gordillo K, Segovia J, Shibayama M, Vergara P, Moreno MG, Muriel P. Curcumin protects against acute liver damage in the rat by inhibiting NF- $\kappa B$, proinflammatory cytokines production and oxidative stress. Biochimica et Biophysica Acta (BBA)-General Subjects. 2007;1770(6):989-96.

84. Yeh $\mathrm{C}-\mathrm{H}$, Chen T-P, Wu Y-C, Lin Y-M, Lin PJ. Inhibition of NFkB activation with curcumin attenuates plasma inflammatory cytokines surge and cardiomyocytic apoptosis following cardiac ischemia/reperfusion1. Journal of Surgical Research. 2005;125(1):109-16.

85. Killian PH, Kronski E, Michalik KM, Barbieri O, Astigiano S, Sommerhoff CP, et al. Curcumin inhibits prostate cancer metastasis in vivo by targeting the inflammatory cytokines CXCL1 and-2. Carcinogenesis. 2012;33(12):2507-19.

86. Sunagawa Y, Wada H, Suzuki H, Sasaki H, Imaizumi A, Fukuda H, et al. A novel drug delivery system of oral curcumin markedly improves efficacy of treatment for heart failure after myocardial infarction in rats. Biological and Pharmaceutical Bulletin. 2012;35(2):139-44.

87. Chen H-W, Lee J-Y, Huang J-Y, Wang C-C, Chen W-J, Su S-F, et al. Curcumin inhibits lung cancer cell invasion and metastasis through the tumor suppressor HLJ1. Cancer research. 2008;68(18):7428-38.

88. Charoensuk L, Pinlaor P, Prakobwong S, Hiraku Y, Laothong U, Ruangjirachuporn W, et al. Curcumin induces a nuclear factor-erythroid 2-related factor 2-driven response against oxidative and nitrative stress after praziquantel treatment in liver fluke-infected hamsters. International journal for parasitology. 2011;41(6):61526.

89. Awad AS, El-Sharif AA. Curcumin immune-mediated and anti-apoptotic mechanisms protect against renal ischemia/reperfusion and distant organ induced injuries. International immunopharmacology. 2011;11(8):992-6.

90. Kim E-H, Pascua PNQ, Song M-S, Baek YH, Kwon H-I, Park S-J, et al. Immunomodulaton and attenuation of lethal influenza A virus infection by oral administration with KIOM-C. Antiviral research. 2013;98(3):386-93.

91. Jung C-M, Koo B-S, Kang S-Y. Effects of a herbal compound, KIOM-C, on growth performance and immune response in commercial pigs. Journal of Biomedical and Translational Research (JBTR). 2019;20(1):814.

92. Kim A, Im M, Yim N-H, Kim T, Ma JY. A novel herbal medicine, KIOM-C, induces autophagic and apoptotic cell death mediated by activation of JNK and reactive oxygen species in HT1080 human fibrosarcoma cells. PloS one. 2014;9(5).

93. Chung T, Kang T, Lee G, Yu K, Kim H, Ma J. Effects of the novel herbal medicine, KIOM-C, on the growth performance and immune status of porcine circovirus associated disease (PCVAD) affected pigs. Journal of Medicinal Plants Research. 2012;6(28):4456-66.

94. Lezin A, Gillet N, Olindo S, Signate A, Grandvaux N, Verlaeten O, et al. Histone deacetylase-mediated transcriptional activation reduces proviral loads in HTLV-1-associated myelopathy/tropical spastic paraparesis patients. Blood. 2007;110(10):3722-8.

95. Talactac MR, Chowdhury MY, Park M-E, Weeratunga P, Kim T-H, Cho W-K, et al. Antiviral effects of novel herbal medicine KIOM-C, on diverse viruses. PloS one. 2015;10(5).

96. Kim A, Yim N-H, Im M, Jung YP, Kim T, Ma JY. Suppression of the invasive potential of highly malignant tumor cells by KIOM-C, a novel herbal medicine, via inhibition of NF- $\kappa$ B activation and MMP-9 expression. Oncology reports. 2014;31(1):287-97.

97. $\mathrm{Pu} \mathrm{H}-\mathrm{L}$, Huang $\mathrm{X}$, Zhao J-H, Hong A. Bergenin is the antiarrhythmic principle of Fluggea virosa. Planta Medica. 2002;68(04):372-4.

98. Takahashi H, Kosaka M, Watanabe Y, Nakade K, Fukuyama Y. Synthesis and neuroprotective activity of bergenin derivatives with antioxidant activity. Bioorganic \& medicinal chemistry. 2003;11(8):1781-8. 
99. Nazir N, Koul S, Qurishi MA, Taneja SC, Ahmad SF, Bani S, et al. Immunomodulatory effect of bergenin and norbergenin against adjuvant-induced arthritis-A flow cytometric study. Journal of Ethnopharmacology. 2007;112(2):401-5.

100. Yang S, Yu Z, Wang L, Yuan T, Wang X, Zhang X, et al. The natural product bergenin ameliorates lipopolysaccharide-induced acute lung injury by inhibiting NF-kappaB activition. Journal of ethnopharmacology. 2017;200:147-55.

101. Wang K, Li Y-f, Lv Q, Li X-m, Dai Y, Wei Z-f. Bergenin, acting as an agonist of PPAR $\gamma$, ameliorates experimental colitis in mice through improving expression of SIRT1, and therefore inhibiting NF-kB-mediated macrophage activation. Frontiers in pharmacology. 2018;8:981.

102. Gao X-j, Guo M-y, Zhang Z-c, Wang T-c, Cao Y-g, Zhang N-s. Bergenin plays an anti-inflammatory role via the modulation of MAPK and NF- $\mathrm{kB}$ signaling pathways in a mouse model of LPS-induced mastitis. Inflammation. 2015;38(3):1142-50.

103. Adaramoye O, Nwaneri V, Anyanwu K, Farombi E, Emerole G. Possible anti-atherogenic effect of kolaviron (a Garcinia kola seed extract) in hypercholesterolaemic rats. Clinical and experimental pharmacology and physiology. 2005;32(1-2):40-6.

104. Ewenighi C, Dimkpa U. Estimation of glucose level and body weight in Alloxan Induced Diabetic Rat treated with Aqueous extract of Garcinia Kola. 2015.

105. Olasope ${ }^{1} \mathrm{~T}$, Suliaman KW. Effect of protein deficiency on teratogenicity obtained from the ethanolic extract of the seed of Garcinia kola.

106. Farombi EO, Shrotriya S, Surh Y-J. Kolaviron inhibits dimethyl nitrosamine-induced liver injury by suppressing COX-2 and iNOS expression via NF- $\kappa B$ and AP-1. Life sciences. 2009;84(5-6):149-55.

107. Abarikwu SO, Farombi EO, Kashyap MP, Pant AB. Kolaviron protects apoptotic cell death in PC12 cells exposed to atrazine. Free radical research. 2011;45(9):1061-73.

108. Awogbindin IO, Olaleye DO, Farombi EO. Mechanistic perspective of the oxido-immunopathologic resolution property of kolaviron in mice influenza pneumonitis. Apmis. 2017;125(3):184-96.

109. Mou Z, Lv Z, Li Y, Wang M, Xu Q, Yu X. Clinical effect of shenfu injection in patients with septic shock: a meta-analysis and systematic review. Evidence-Based Complementary and Alternative Medicine. $2015 ; 2015$.

110. Ikeda H, Suzuki Y, Suzuki M, Koike M, Tamura J, Tong J, et al. Apoptosis is a major mode of cell death caused by ischaemia and ischaemia/reperfusion injury to the rat intestinal epithelium. Gut. 1998;42(4):530-7.

111. Xia Z, Zheng L. Shenfu Injection for prevention and treatment of ischemia reperfusion injury of intestinal mucosa. Chin J Trauma. 2001;17:235-6.

112. Qian Y, Sun J, Wang Z, Yang J. Shen-Fu attenuates endotoxin-induced acute lung injury in rats. The American journal of Chinese medicine. 2006;34(04):613-21.

113. Zhang Q, Li C-s, Wang S, Gu W. Effects of Chinese Medicine Shen-Fu Injection (参附注射液) on the expression of inflammatory cytokines and complements during post-resuscitation immune dysfunction in a porcine model. Chinese journal of integrative medicine. 2016;22(2):101-9.

114. Jarrar D, Kuebler JF, Rue III LW, Matalon S, Wang P, Bland KI, et al. Alveolar macrophage activation after trauma-hemorrhage and sepsis is dependent on NF- $\mathrm{kB}$ and MAPK/ERK mechanisms. American Journal of Physiology-Lung Cellular and Molecular Physiology. 2002;283(4):L799-L805.

115. Srinivasa Reddy P, Jamil K, Madhusudhan P, Anjani G, Das B. Antibacterial activity of isolates from Piper longum and Taxus baccata. Pharmaceutical biology. 2001;39(3):236-8.

116. Bezerra DP, Pessoa C, de Moraes MO, Saker-Neto N, Silveira ER, Costa-Lotufo LV. Overview of the therapeutic potential of piplartine (piperlongumine). European Journal of Pharmaceutical Sciences. 2013;48(3):453-63.

117. Bernard C, Krishanmurty H, Chauret D, Durst T, Philogene B, Sanchez-Vindas P, et al. Insecticidal defenses of Piperaceae from the neotropics. Journal of Chemical Ecology. 1995;21(6):801-14.

118. Duh C-Y, Wu Y-C, Wang S-K. Cytotoxic pyridone alkaloids from the leaves of Piper aborescens. Journal of natural products. 1990;53(6):1575-7.

119. Tsai I-L, Lee F-P, Wu C-C, Duh C-Y, Ishikawa T, Chen J-J, et al. New cytotoxic cyclobutanoid amides, a new furanoid lignan and anti-platelet aggregation constituents from Piper arborescens. Planta medica. 2005;71(06):535-42. 
120. Rao VR, Muthenna P, Shankaraiah G, Akileshwari C, Babu KH, Suresh G, et al. Synthesis and biological evaluation of new piplartine analogues as potent aldose reductase inhibitors (ARIs). European journal of medicinal chemistry. 2012;57:344-61.

121. Seo YH, Kim J-K, Jun J-G. Synthesis and biological evaluation of piperlongumine derivatives as potent anti-inflammatory agents. Bioorganic \& medicinal chemistry letters. 2014;24(24):5727-30.

122. Lairmore MD, Anupam R, Bowden N, Haines R, Haynes II RA, Ratner L, et al. Molecular determinants of human T-lymphotropic virus type 1 transmission and spread. Viruses. 2011;3(7):1131-65.

123. Dan HC, Cooper MJ, Cogswell PC, Duncan JA, Ting JP-Y, Baldwin AS. Akt-dependent regulation of $\mathrm{NF}-\kappa \mathrm{B}$ is controlled by mTOR and Raptor in association with IKK. Genes \& development. 2008;22(11):1490500 .

124. Ginzburg S, Golovine KV, Makhov PB, Uzzo RG, Kutikov A, Kolenko VM. Piperlongumine inhibits $\mathrm{NF}-\kappa \mathrm{B}$ activity and attenuates aggressive growth characteristics of prostate cancer cells. The Prostate. 2014;74(2):177-86.

125. Kim N, Do J, Bae J-s, Jin HK, Kim J-H, Inn K-S, et al. Piperlongumine inhibits neuroinflammation via regulating NF- $\mathrm{kB}$ signaling pathways in lipopolysaccharide-stimulated BV2 microglia cells. Journal of pharmacological sciences. 2018;137(2):195-201.

126. Lee W, Yoo H, Kim JA, Lee S, Jee J-G, Lee MY, et al. Barrier protective effects of piperlonguminine in LPS-induced inflammation in vitro and in vivo. Food and chemical toxicology. 2013;58:149-57.

127. Sun J, Xu P, Du X, Zhang Q, Zhu Y. Piperlongumine attenuates collagen-induced arthritis via expansion of myeloid-derived suppressor cells and inhibition of the activation of fibroblast-like synoviocytes. Molecular medicine reports. 2015;11(4):2689-94.

128. Lu C, Zhang B, Xu T, Zhang W, Bai B, Xiao Z, et al. Piperlongumine reduces ovalbumin-induced asthma and airway inflammation by regulating nuclear factor- $\mathrm{kB}$ activation. International journal of molecular medicine. 2019;44(5):1855-65.

129. Thatikonda S, Pooladanda V, Sigalapalli DK, Godugu C. Piperlongumine regulates epigenetic modulation and alleviates psoriasis-like skin inflammation via inhibition of hyperproliferation and inflammation. Cell Death \& Disease. 2020;11(1):1-17.

130. Yeh CH, Yang ML, Lee CY, Yang CP, Li YC, Chen CJ, et al. Wogonin attenuates endotoxin-induced prostaglandin E2 and nitric oxide production via Src-ERK1/2-NFאB pathway in BV-2 microglial cells. Environmental toxicology. 2014;29(10):1162-70.

131. Gibbons HM, Dragunow M. Microglia induce neural cell death via a proximity-dependent mechanism involving nitric oxide. Brain research. 2006;1084(1):1-15.

132. Lu H, Gao F, Shu G, Xia G, Shao Z, Lu H, et al. Wogonin inhibits the proliferation of myelodysplastic syndrome cells through the induction of cell cycle arrest and apoptosis. Molecular medicine reports. 2015;12(5):7285-92.

133. Piao HZ, Choi IY, Park J-S, Kim H-S, Cheong JH, Son KH, et al. Wogonin inhibits microglial cell migration via suppression of nuclear factor-kappa B activity. International immunopharmacology. 2008;8(12):1658-62.

134. Lin C-M, Chen Y-H, Ong J-R, Ma H-P, Shyu K-G, Bai K-J. Functional role of wogonin in antiangiogenesis. The American journal of Chinese medicine. 2012;40(02):415-27.

135. Chi YS, Lim H, Park H, Kim HP. Effects of wogonin, a plant flavone from Scutellaria radix, on skin inflammation: in vivo regulation of inflammation-associated gene expression. Biochemical pharmacology. 2003;66(7):1271-8.

136. Wang W, Xia T, Yu X. Wogonin suppresses inflammatory response and maintains intestinal barrier function via TLR4-MyD88-TAK1-mediated NF- $\kappa B$ pathway in vitro. Inflammation Research. 2015;64(6):42331.

137. Chen C, Guo D, Lu G. Wogonin protects human retinal pigment epithelium cells from LPS-induced barrier dysfunction and inflammatory responses by regulating the TLR4/NF- $\kappa B$ signaling pathway. Molecular medicine reports. 2017;15(4):2289-95.

138. Chen S, Xiong J, Zhan Y, Liu W, Wang X. Wogonin inhibits LPS-induced inflammatory responses in rat dorsal root ganglion neurons via inhibiting TLR4-MyD88-TAK1-mediated NF- $\kappa B$ and MAPK signaling pathway. Cellular and molecular neurobiology. 2015;35(4):523-31.

139. Shapiro H, Lev S, Cohen J, Singer P. Polyphenols in the prevention and treatment of sepsis syndromes: rationale and pre-clinical evidence. Nutrition. 2009;25(10):981-97. 
140. Kanadaswami C, Lee L-T, Lee P-PH, Hwang J-J, Ke F-C, Huang Y-T, et al. The antitumor activities of flavonoids. In vivo. 2005;19(5):895-909.

141. Tseng T-L, Chen M-F, Tsai M-J, Hsu Y-H, Chen C-P, Lee TJ. Oroxylin-A rescues LPS-induced acute lung injury via regulation of NF- $\kappa B$ signaling pathway in rodents. PLoS One. 2012;7(10).

142. Vandenbroucke E, Mehta D, Minshall R, Malik AB. Regulation of endothelial junctional permeability. Annals of the new York Academy of Sciences. 2008;1123(1):134-45.

143. Chen Y-C, Yang L-L, Lee TJ. Oroxylin A inhibition of lipopolysaccharide-induced iNOS and COX-2 gene expression via suppression of nuclear factor- $\mathrm{kB}$ activation. Biochemical pharmacology. 2000;59(11):1445-57.

144. Zhou D-G, Diao B-Z, Zhou W, Feng J-L. Oroxylin A inhibits allergic airway inflammation in ovalbumin (OVA)-induced asthma murine model. Inflammation. 2016;39(2):867-72.

145. Yao J, Hu R, Sun J, Lin B, Zhao L, Sha Y, et al. Oroxylin a prevents inflammation-related tumor through down-regulation of inflammatory gene expression by inhibiting NF- $\mathrm{BB}$ signaling. Molecular carcinogenesis. 2014;53(2):145-58.

146. Li Y, Gan L, Li GQ, Deng L, Zhang X, Deng Y. Pharmacokinetics of plantamajoside and acteoside from Plantago asiatica in rats by liquid chromatography-mass spectrometry. Journal of pharmaceutical and biomedical analysis. 2014;89:251-6.

147. Pei S, Yang X, Wang H, Zhang H, Zhou B, Zhang D, et al. Plantamajoside, a potential anti-tumor herbal medicine inhibits breast cancer growth and pulmonary metastasis by decreasing the activity of matrix metalloproteinase-9 and-2. BMC cancer. 2015;15(1):965.

148. Ravn H, Brimer L. Structure and antibacterial activity of plantamajoside, a caffeic acid sugar ester from Plantago major subs major. Phytochemistry. 1988;27(11):3433-7.

149. Samuelsen AB. The traditional uses, chemical constituents and biological activities of Plantago major L. A review. Journal of ethnopharmacology. 2000;71(1-2):1-21.

150. Li X, Chen D, Li M, Gao X, Shi G, Zhao H. Plantamajoside inhibits lipopolysaccharide-induced epithelial-mesenchymal transition through suppressing the NF-kB/IL-6 signaling in esophageal squamous cell carcinoma cells. Biomedicine \& Pharmacotherapy. 2018;102:1045-51.

151. Park BG, Lee HS, Jung SH, Hong CO, Won HJ, Park HY, et al. A 90 day repeated oral toxicity study on plantamajoside concentrate from Plantago asiatica. Phytotherapy Research: An International Journal Devoted to Pharmacological and Toxicological Evaluation of Natural Product Derivatives. 2007;21(12):111823.

152. Qiushi W, Guanghua L, Guangquan X. Acanthoic acid ameliorates lipopolysaccharide-induced acute lung injury. European journal of pharmacology. 2015;750:32-8.

153. Crespo I, García-Mediavilla MV, Gutiérrez B, Sánchez-Campos S, Tuñón MJ, González-Gallego J. A comparison of the effects of kaempferol and quercetin on cytokine-induced pro-inflammatory status of cultured human endothelial cells. British journal of nutrition. 2008;100(5):968-76.

154. Wei D, Huang Z. Anti-inflammatory effects of triptolide in LPS-induced acute lung injury in mice. Inflammation. 2014;37(4):1307-16.

155. Reutershan J, Basit A, Galkina EV, Ley K. Sequential recruitment of neutrophils into lung and bronchoalveolar lavage fluid in LPS-induced acute lung injury. American Journal of Physiology-Lung Cellular and Molecular Physiology. 2005;289(5):L807-L15.

156. Wu H, Zhao G, Jiang K, Chen X, Zhu Z, Qiu C, et al. Plantamajoside ameliorates lipopolysaccharideinduced acute lung injury via suppressing NF- $\mathrm{BB}$ and MAPK activation. International immunopharmacology. 2016;35:315-22.

157. Joh E-H, Gu W, Kim D-H. Echinocystic acid ameliorates lung inflammation in mice and alveolar macrophages by inhibiting the binding of LPS to TLR4 in NF-אB and MAPK pathways. Biochemical pharmacology. 2012;84(3):331-40.

158. Son W-r, Nam M-H, Hong C-O, Kim Y, Lee K-W. Plantamajoside from Plantago asiatica modulates human umbilical vein endothelial cell dysfunction by glyceraldehyde-induced AGEs via MAPK/NF- $\mathrm{KB}$. BMC complementary and alternative medicine. 2017;17(1):66.

159. Ma C, Ma W. Plantamajoside inhibits lipopolysaccharide-induced MUC5AC expression and inflammation through suppressing the PI3K/Akt and NF- $\mathrm{KB}$ signaling pathways in human airway epithelial cells. Inflammation. 2018;41(3):795-802.

160. $\mathrm{Ng} \mathrm{T}$, Liu F, Wang Z. Antioxidative activity of natural products from plants. Life sciences. 2000;66(8):709-23. 
161. Özçelik B, Kartal M, Orhan I. Cytotoxicity, antiviral and antimicrobial activities of alkaloids, flavonoids, and phenolic acids. Pharmaceutical biology. 2011;49(4):396-402.

162. Lee EJ, Kim DI, Kim WJ, Moon SK. Naringin inhibits matrix metalloproteinase-9 expression and AKT phosphorylation in tumor necrosis factor- $\alpha$-induced vascular smooth muscle cells. Molecular nutrition \& food research. 2009;53(12):1582-91.

163. Bi C, Jiang Y, Fu T, Hao Y, Zhu X, Lu Y. Naringin inhibits lipopolysaccharide-induced damage in human umbilical vein endothelial cells via attenuation of inflammation, apoptosis and MAPK pathways. Cytotechnology. 2016;68(4):1473-87.

164. Jung UJ, Lee M-K, Jeong K-S, Choi M-S. The hypoglycemic effects of hesperidin and naringin are partly mediated by hepatic glucose-regulating enzymes in C57BL/KsJ-db/db mice. The Journal of nutrition. 2004;134(10):2499-503.

165. Shin YW, Bok SH, Jeong TS, Bae KH, Jeoung NH, Choi MS, et al. Hypocholesterolemic effect of naringin associated with hepatic cholesterol regulating enzyme changes in rats. International journal for vitamin and nutrition research Internationale Zeitschrift fur Vitamin-und Ernahrungsforschung Journal international de vitaminologie et de nutrition. 1999;69(5):341-7.

166. Wong RW, Rabie B, Bendeus M, Hägg U. The effects of Rhizoma Curculiginis and Rhizoma Drynariae extracts on bones. Chinese medicine. 2007;2(1):13.

167. Liu Y, Wu H, Nie Y-c, Chen J-1, Su W-w, Li P-b. Naringin attenuates acute lung injury in LPS-treated mice by inhibiting NF- $\mathrm{KB}$ pathway. International Immunopharmacology. 2011;11(10):1606-12.

168. Liu Y, Su W-W, Wang S, Li P-B. Naringin inhibits chemokine production in an LPS-induced RAW 264.7 macrophage cell line. Molecular medicine reports. 2012;6(6):1343-50.

169. Gil M, Kim YK, Hong SB, Lee KJ. Naringin decreases TNF- $\alpha$ and HMGB1 release from LPSstimulated macrophages and improves survival in a CLP-induced sepsis mice. PLoS One. 2016;11(10).

170. Kanno S-i, Shouji A, Tomizawa A, Hiura T, Osanai Y, Ujibe M, et al. Inhibitory effect of naringin on lipopolysaccharide (LPS)-induced endotoxin shock in mice and nitric oxide production in RAW 264.7 macrophages. Life Sciences. 2006;78(7):673-81.

171. Chen H, Du Q. Potential natural compounds for preventing 2019-nCoV infection. Preprints. 2020.

172. Ramos-Benitez MJ, Ruiz-Jimenez C, Rosado-Franco JJ, Ramos-Pérez WD, Mendez LB, Osuna A, et al. Fh15 Blocks the Lipopolysaccharide-Induced Cytokine Storm While Modulating Peritoneal Macrophage Migration and CD38 Expression within Spleen Macrophages in a Mouse Model of Septic Shock. MSphere. 2018;3(6):e00548-18.

173. Cheng L, Zheng W, Li M, Huang J, Bao S, Xu Q, et al. Citrus Fruits Are Rich in Flavonoids for Immunoregulation and Potential Targeting ACE2. 2020.

174. Kuhn JH, Radoshitzky SR, Li W, Wong SK, Choe H, Farzan M. The SARS Coronavirus receptor ACE 2 A potential target for antiviral therapy. New Concepts of Antiviral Therapy: Springer; 2006. p. 397-418.

175. Vincent MJ, Bergeron E, Benjannet S, Erickson BR, Rollin PE, Ksiazek TG, et al. Chloroquine is a potent inhibitor of SARS coronavirus infection and spread. Virology journal. 2005;2(1):69.

176. Gilbert L, He X, Farmer P, Boden S, Kozlowski M, Rubin J, et al. Inhibition of osteoblast differentiation by tumor necrosis factor- $\alpha$. Endocrinology. 2000;141(11):3956-64.

177. Cao X, Lin W, Liang C, Zhang D, Yang F, Zhang Y, et al. Naringin rescued the TNF- a -induced inhibition of osteogenesis of bone marrow-derived mesenchymal stem cells by depressing the activation of NFкВ signaling pathway. Immunologic research. 2015;62(3):357-67.

178. Sahu BD, Tatireddy S, Koneru M, Borkar RM, Kumar JM, Kuncha M, et al. Naringin ameliorates gentamicin-induced nephrotoxicity and associated mitochondrial dysfunction, apoptosis and inflammation in rats: possible mechanism of nephroprotection. Toxicology and applied pharmacology. 2014;277(1):8-20.

179. Öztürk N, Korkmaz S, Öztürk Y. Wound-healing activity of St. John's Wort (Hypericum perforatum L.) on chicken embryonic fibroblasts. Journal of ethnopharmacology. 2007;111(1):33-9.

180. Lee I-A, Hyam SR, Jang S-E, Han MJ, Kim D-H. Ginsenoside Re ameliorates inflammation by inhibiting the binding of lipopolysaccharide to TLR4 on macrophages. Journal of agricultural and food chemistry. 2012;60(38):9595-602.

181. Paik S, Choe JH, Choi G-E, Kim J-E, Kim J-M, Song GY, et al. Rg6, a rare ginsenoside, inhibits systemic inflammation through the induction of interleukin-10 and microRNA-146a. Scientific reports. 2019;9(1):1-15. 
182. Zhang R, Ai X, Duan Y, Xue M, He W, Wang C, et al. Kaempferol ameliorates H9N2 swine influenza virus-induced acute lung injury by inactivation of TLR4/MyD88-mediated NF- $\mathrm{kB}$ and MAPK signaling pathways. Biomedicine \& pharmacotherapy. 2017;89:660-72.

183. Chen X, Yang X, Liu T, Guan M, Feng X, Dong W, et al. Kaempferol regulates MAPKs and NF-кB signaling pathways to attenuate LPS-induced acute lung injury in mice. International immunopharmacology. 2012;14(2):209-16.

184. Zamani Taghizadeh Rabe S, Ghazanfari T, Siadat Z, Rastin M, Zamani Taghizadeh Rabe S, Mahmoudi M. Anti-inflammatory effect of garlic $14-\mathrm{kDa}$ protein on LPS-stimulated-J774A. 1 macrophages. Immunopharmacology and immunotoxicology. 2015;37(2):158-64.

185. Islam MS, Miao L, Yu H, Han Z, Sun H. Ethanol extract of Illicium henryi attenuates LPS-induced acute kidney injury in mice via regulating inflammation and oxidative stress. Nutrients. 2019;11(6):1412.

186. Islam MS, Yu H, Miao L, Liu Z, He Y, Sun H. Hepatoprotective Effect of the Ethanol Extract of Illicium henryi against Acute Liver Injury in Mice Induced by Lipopolysaccharide. Antioxidants. 2019;8(10):446.

187. Traboulsi H, Cloutier A, Boyapelly K, Bonin M-A, Marsault É, Cantin AM, et al. The flavonoid isoliquiritigenin reduces lung inflammation and mouse morbidity during influenza virus infection. Antimicrobial agents and chemotherapy. 2015;59(10):6317-27.

188. Ding Y, Zeng L, Li R, Chen Q, Zhou B, Chen Q, et al. The Chinese prescription lianhuaqingwen capsule exerts anti-influenza activity through the inhibition of viral propagation and impacts immune function. BMC Complement Altern Med. 2017;17(1):130.

189. Runfeng L, Yunlong H, Jicheng H, Weiqi P, Qinhai M, Yongxia S, et al. Lianhuaqingwen exerts antiviral and anti-inflammatory activity against novel coronavirus (SARS-CoV-2). Pharmacological Research. 2020:104761.

190. Dong L, Xia J-w, Gong Y, Chen Z, Yang H-h, Zhang J, et al. Effect of lianhuaqingwen capsules on airway inflammation in patients with acute exacerbation of chronic obstructive pulmonary disease. EvidenceBased Complementary and Alternative Medicine. 2014;2014.

191. Li Q, Yin J, Ran Q-S, Yang Q, Liu L, Zhao Z, et al. Efficacy and mechanism of Lianhua Qingwen Capsules (LHQW) on chemotaxis of macrophages in acute lung injury (ALI) animal model. Zhongguo Zhong yao za zhi= Zhongguo zhongyao zazhi= China journal of Chinese materia medica. 2019;44(11):2317-23.

192. Fu Y, Liu B, Zhang N, Liu Z, Liang D, Li F, et al. Magnolol inhibits lipopolysaccharide-induced inflammatory response by interfering with TLR4 mediated NF- $\mathrm{BB}$ and MAPKs signaling pathways. Journal of ethnopharmacology. 2013;145(1):193-9.

193. Haque MA, Jantan I, Harikrishnan H, Wahab SMA. Magnoflorine enhances LPS-activated proinflammatory responses via MyD88-dependent pathways in U937 macrophages. Planta medica. 2018;84(17):1255-64.

194. Guo S, Jiang K, Wu H, Yang C, Yang Y, Yang J, et al. Magnoflorine ameliorates lipopolysaccharideinduced acute lung injury via suppressing NF- $\mathrm{BB}$ and MAPK activation. Frontiers in pharmacology. 2018;9:982.

195. Wei W, Wan H, Peng X, Zhou H, Lu Y, He Y. Antiviral effects of Ma Huang Tang against H1N1 influenza virus infection in vitro and in an ICR pneumonia mouse model. Biomedicine \& Pharmacotherapy. 2018;102:1161-75.

196. Wei W, Du H, Shao C, Zhou H, Lu Y, Yu L, et al. Screening of Antiviral Components of Ma Huang Tang and Investigation on the Ephedra Alkaloids Efficacy on Influenza Virus Type A. Frontiers in pharmacology. 2019;10.

197. Wei W, Wan H, Yu L, Lu Y, He Y. Effect and mechanism of Mahuang Tang against influenza A/H1N1 virus in vitro. Zhongguo Zhong yao za zhi= Zhongguo zhongyao zazhi= China journal of Chinese materia medica. 2018;43(3):563-70.

198. Ernst E. The efficacy of herbal medicine--an overview. Fundam Clin Pharmacol. 2005;19(4):405-9.

199. Rivlin RS. Is garlic alternative medicine? J Nutr. 2006;136(3 Suppl):713s-5s.

200. Bhagyalakshmi N, Thimmaraju R, Venkatachalam L, Murthy KN, Sreedhar RV. Nutraceutical applications of garlic and the intervention of biotechnology. Crit Rev Food Sci Nutr. 2005;45(7-8):607-21.

201. Bolton S, Null G, Troetel WM. The medical uses of garlic--fact and fiction. Am Pharm. 1982;Ns22(8):40-3.

202. Corzo-Martínez M, Corzo N, Villamiel M. Biological properties of onions and garlic. Trends in Food Science \& Technology. 2007;18:609-25. 
203. Ghazanfari T, Hassan ZM, Ebrahimi M. Immunomodulatory activity of a protein isolated from garlic extract on delayed type hypersensitivity. Int Immunopharmacol. 2002;2(11):1541-9.

204. Ahmadabad HN, Hassan ZM, Safari E, Bozorgmehr M, Ghazanfari T, Moazzeni SM. Evaluation of the immunomodulatory effect of the $14 \mathrm{kDa}$ protein isolated from aged garlic extract on dendritic cells. Cell Immunol. 2011;269(2):90-5.

205. Daneshmandi S, Hajimoradi M, Ahmadabad HN, Hassan ZM, Roudbary M, Ghazanfari T. Effect of 14$\mathrm{kDa}$ and $47-\mathrm{kDa}$ protein molecules of age garlic extract on peritoneal macrophages. Immunopharmacol Immunotoxicol. 2011;33(1):21-7.

206. Rabe SZ, Ghazanfari T, Siadat Z, Rastin M, Rabe SZ, Mahmoudi M. Anti-inflammatory effect of garlic 14-kDa protein on LPS-stimulated-J774A.1 macrophages. Immunopharmacol Immunotoxicol. 2015;37(2):15864.

207. Chen Y, Gao A, Gong J, Yang L, Wang M, Yang W, et al. An overview of pharmaceutical research on Illicium henryi Diels. J Anhui Agric Sci. 2011;39:8376-7.

208. Liu J-F, Jiang Z-Y, Zhang Q, Shi Y, Ma Y-B, Xie M-J, et al. Henrylactones A-E and anti-HBV constituents from Illicium henryi. Planta medica. 2010;76(02):152-8.

209. Xiang WJ, Ma L, Hu LH. Neolignans and flavonoids from the root bark of Illicium henryi. Fitoterapia. 2010;81(8):1228-31.

210. Song TF, Zhang WD, Xia XH, Shen YH, Liu CM, Lin S, et al. Two new acorane sesquiterpenes from Illicium henryi. Arch Pharm Res. 2009;32(9):1233-6.

211. Liu JF, Jiang ZY, Zhang Q, Shi Y, Ma YB, Xie MJ, et al. Henrylactones A-E and anti-HBV constituents from Illicium henryi. Planta Med. 2010;76(2):152-8.

212. Yang L, Takai H, Utsunomiya T, Li X, Li Z, Wang Z, et al. Kaempferol stimulates bone sialoprotein gene transcription and new bone formation. J Cell Biochem. 2010;110(6):1342-55.

213. Cheng P, Wang T, Li W, Muhammad I, Wang H, Sun X, et al. Baicalin alleviates lipopolysaccharideinduced liver inflammation in chicken by suppressing TLR4-mediated NF- $\mathrm{kB}$ pathway. Frontiers in pharmacology. 2017;8:547.

214. Latha S, Chaudhary S, Ray RS. Hydroalcoholic extract of Stevia rebaudiana bert. leaves and stevioside ameliorates lipopolysaccharide induced acute liver injury in rats. Biomed Pharmacother. 2017;95:1040-50.

215. Yang YQ, Yan XT, Wang K, Tian RM, Lu ZY, Wu LL, et al. Triptriolide Alleviates Lipopolysaccharide-Induced Liver Injury by Nrf2 and NF-kB Signaling Pathways. Front Pharmacol. 2018;9:999.

216. Xu D, Xu M, Jeong S, Qian Y, Wu H, Xia Q, et al. The Role of Nrf2 in Liver Disease: Novel Molecular Mechanisms and Therapeutic Approaches. Front Pharmacol. 2018;9:1428.

217. Kim J, Park S, Yun K-J, Cho Y-W, Park H-J, Lee K-T. Isoliquiritigenin isolated from the roots of Glycyrrhiza uralensis inhibits LPS-induced iNOS and COX-2 expression via the attenuation of NF-kB in RAW 264.7 macrophages. European journal of pharmacology. 2008;584:175-84.

218. Kumar S, Sharma A, Madan B, Singhal V, Ghosh B. Isoliquiritigenin inhibits IкB kinase activity and ROS generation to block TNF- $\alpha$ induced expression of cell adhesion molecules on human endothelial cells. Biochemical pharmacology. 2007;73(10):1602-12.

219. Lee SH, Kim JY, Seo GS, Kim YC, Sohn DH. Isoliquiritigenin, from Dalbergia odorifera, up-regulates anti-inflammatory heme oxygenase-1 expression in RAW264.7 macrophages. Inflamm Res. 2009;58(5):257-62.

220. Chen H, Zhang B, Yuan X, Yao Y, Zhao H, Sun X, et al. Isoliquiritigenin-induced effects on Nrf2 mediated antioxidant defence in the HL-60 cell monocytic differentiation. Cell Biol Int. 2013;37(11):1215-24.

221. Zhou L, Tang Y-P, Gao L, Fan X-S, Liu C-M, Wu D-K. Separation, characterization and dose-effect relationship of the PPAR $\gamma$-activating bio-active constituents in the chinese herb formulation 'San-ao decoction'. Molecules. 2009; 14(10):3942-51.

222. Ryu YB, Kim JH, Park SJ, Chang JS, Rho MC, Bae KH, et al. Inhibition of neuraminidase activity by polyphenol compounds isolated from the roots of Glycyrrhiza uralensis. Bioorg Med Chem Lett. 2010;20(3):971-4.

223. Hung HC, Tseng CP, Yang JM, Ju YW, Tseng SN, Chen YF, et al. Aurintricarboxylic acid inhibits influenza virus neuraminidase. Antiviral Res. 2009;81(2):123-31.

224. Duan ZP, Jia ZH, Zhang J, Liu S, Chen Y, Liang LC, et al. Natural herbal medicine Lianhuaqingwen capsule anti-influenza A (H1N1) trial: a randomized, double blind, positive controlled clinical trial. Chin Med J (Engl). 2011;124(18):2925-33. 
225. Xu J, Qin X, Wang J, Zhang S, Zhong Y, Ren L, et al. Chinese guidelines for the diagnosis and comprehensive treatment of hepatic metastasis of colorectal cancer. J Cancer Res Clin Oncol. 2011;137(9):1379-96.

226. $\mathrm{Lu} \mathrm{H}$. Drug treatment options for the 2019-new coronavirus (2019-nCoV). Biosci Trends. 2020;14(1):69-71.

227. Runfeng L, Yunlong H, Jicheng H, Weiqi P, Qinhai M, Yongxia S, et al. Lianhuaqingwen exerts antiviral and anti-inflammatory activity against novel coronavirus (SARS-CoV-2). Pharmacological research. 2020;156:104761.

228. Ren JL, Zhang AH, Wang XJ. Traditional Chinese medicine for COVID-19 treatment. Pharmacol Res. 2020;155:104743.

229. Yang Y, Islam MS, Wang J, Li Y, Chen X. Traditional Chinese Medicine in the Treatment of Patients Infected with 2019-New Coronavirus (SARS-CoV-2): A Review and Perspective. International Journal of Biological Sciences. 2020;16:1708-17.

230. Rashid MA, Gustafson KR, Kashman Y, Cardellina JH, McMahon JB, Boyd MR. Anti-HIV alkaloids from Toddalia asiatica. Natural product letters. 1995;6(2):153-6.

231. Chen CR, Tan R, Qu WM, Wu Z, Wang Y, Urade Y, et al. Magnolol, a major bioactive constituent of the bark of Magnolia officinalis, exerts antiepileptic effects via the GABA/benzodiazepine receptor complex in mice. Br J Pharmacol. 2011;164(5):1534-46.

232. Matsuda H, Kageura T, Oda M, Morikawa T, Sakamoto Y, Yoshikawa M. Effects of constituents from the bark of Magnolia obovata on nitric oxide production in lipopolysaccharide-activated macrophages. Chem Pharm Bull (Tokyo). 2001;49(6):716-20.

233. Nakazawa T, Yasuda T, Ohsawa K. Metabolites of orally administered Magnolia officinalis extract in rats and man and its antidepressant-like effects in mice. J Pharm Pharmacol. 2003;55(11):1583-91.

234. El Tahir KEH. Pharmacological Actions of Magnoflorine and Aristolochic Acid-1 Isolated from the Seeds of Aristolochia bracteata. International Journal of Pharmacognosy. 1991;29(2):101-10.

235. Zheng M, Zhou H, Wan H, Chen YL, He Y. Effects of herbal drugs in Mahuang decoction and their main components on intestinal transport characteristics of Ephedra alkaloids evaluated by a Caco-2 cell monolayer model. J Ethnopharmacol. 2015;164:22-9.

236. Ma CH, Ma ZQ, Fu Q, Ma SP. Ma Huang Tang ameliorates asthma though modulation of Th1/Th2 cytokines and inhibition of Th17 cells in ovalbumin-sensitized mice. Chin J Nat Med. 2014;12(5):361-6.

237. Wei W-Y, Wan H-T, Yu L, Lu Y-Y, He Y. Effect and mechanism of Mahuang Tang against influenza A/H1N1 virus in vitro. Zhongguo Zhong yao za zhi= Zhongguo zhongyao zazhi= China journal of Chinese materia medica. 2018;43(3):563-70.

238. Abarikwu SO. Kolaviron, a natural flavonoid from the seeds of Garcinia kola, reduces LPS-induced inflammation in macrophages by combined inhibition of IL-6 secretion, and inflammatory transcription factors, ERK1/2, NF-kB, p38, Akt, pc-JUN and JNK. Biochimica et Biophysica Acta (BBA)-General Subjects. 2014;1840(7):2373-81.

239. 张茜, 李春盛, 王炼, 顾伟. Effects of Chinese Medicine Shen-Fu Injection (参附注射液) on the Expression of Inflammatory Cytokines and Complements during Post-Resuscitation Immune Dysfunction in A Porcine Model. Chinese Journal of Integrative Medicine. 2016(2):4. 